\title{
Periodontal Wound Healing and Regeneration: Insights for Engineering New Therapeutic Approaches
}

\author{
David Fraser ${ }^{1,2 *}$, Jack Caton ${ }^{2}$ and Danielle S. W. Benoit ${ }^{3,4,5,6,7 *}$ \\ ${ }^{1}$ Translational Biomedical Science, University of Rochester, Rochester, NY, United States, ${ }^{2}$ Eastman Institute for Oral Health, \\ University of Rochester, Rochester, NY, United States, ${ }^{3}$ Department of Biomedical Engineering, University of Rochester, \\ Rochester, NY, United States, ${ }^{4}$ Department of Chemical Engineering, University of Rochester, Rochester, NY, United States, \\ ${ }^{5}$ Materials Science Program, University of Rochester, Rochester, NY, United States, ${ }^{6}$ Center for Oral Biology, University of \\ Rochester, Rochester, NY, United States, ${ }^{7}$ Center for Musculoskeletal Research, University of Rochester, Rochester, NY, \\ United States
}

OPEN ACCESS

Edited by:

Patrick R. Schmidlin,

University of Zurich, Switzerland

Reviewed by:

Andreas Stavropoulos,

Malmö University, Sweden

Alex Solderer

University of Zurich, Switzerland Terukazu Sanui,

Kyushu University, Japan

Olivier Huck

Université de Strasbourg, France

${ }^{*}$ Correspondence:

David Fraser

david_fraser@urmc.rochester.edu

Danielle S. W. Benoit

danielle.benoit@rochester.edu

Specialty section:

This article was submitted to

Periodontics,

a section of the journa

Frontiers in Dental Medicine

Received: 15 November 2021

Accepted: 27 January 2022

Published: 02 March 2022

Citation:

Fraser D, Caton J and Benoit DSW (2022) Periodontal Wound Healing

and Regeneration: Insights for

Engineering New Therapeutic

Approaches.

Front. Dent. Med. 3:815810.

doi: 10.3389/fdmed.2022.815810
Periodontitis is a widespread inflammatory disease that leads to loss of the tooth supporting periodontal tissues. The few therapies available to regenerate periodontal tissues have high costs and inherent limitations, inspiring the development of new approaches. Studies have shown that periodontal tissues have an inherent capacity for regeneration, driven by multipotent cells residing in the periodontal ligament (PDL). The purpose of this review is to describe the current understanding of the mechanisms driving periodontal wound healing and regeneration that can inform the development of new treatment approaches. The biologic basis underlying established therapies such as guided tissue regeneration (GTR) and growth factor delivery are reviewed, along with examples of biomaterials that have been engineered to improve the effectiveness of these approaches. Emerging therapies such as those targeting Wnt signaling, periodontal cell delivery or recruitment, and tissue engineered scaffolds are described in the context of periodontal wound healing, using key in vivo studies to illustrate the impact these approaches can have on the formation of new cementum, alveolar bone, and PDL. Finally, design principles for engineering new therapies are suggested which build on current knowledge of periodontal wound healing and regeneration.

Keywords: periodontal regeneration, guided tissue regeneration (GTR), periodontal wound healing, tissue engineering, scaffolds, periodontal stem cells, growth factors

\section{INTRODUCTION}

The functional periodontium is comprised of alveolar bone, cementum, and the interposed periodontal ligament (PDL) (Figure 1A). This complex is essential for biomechanical tooth function and structural support of the gingival tissues, the junctional epithelium, and connective tissue attachment, which form a barrier against infiltrating bacteria (1). Periodontitis is a destructive inflammatory disease occurring in response to bacterial biofilms on the tooth surface (2) (Figure 1B). While biofilm removal mitigates inflammation and disease progression, loss of alveolar bone surrounding the tooth and destruction of the cementum lining the tooth root surface is irreversible. Following non-surgical biofilm removal (scaling and root planing) or after reflection and replacement of gingival tissues to access root surface biofilms, epithelial tissue forms against the 
tooth root, and fibrous connective tissue fills the residual bone defects $(3,4)$. While such treatments help resolve inflammation, the reparative tissues that form against the root may be prone to future breakdown and reoccurrence of periodontitis $(5,6)$. Resective therapies aiming to eliminate bone defects and these epithelial and connective tissues are effective in preventing the recurrence of periodontitis (Figure 1C) but fail to restore biomechanical tooth support and leave tooth roots exposed to the oral cavity $(7,8)$. As an alternative, reconstructive therapies aimed at periodontal tissue regeneration are an attractive approach for restoring both form and function, and ultimately ensuring long-term periodontal health (9) (Table 1).

An extraordinary volume of work has been performed to understand periodontal wound healing, uncovering an endogenous regenerative potential in the periodontal tissues. Guided tissue regeneration, a biomaterial-based approach for rebuilding new periodontal tissues, has been in clinical use for decades. Yet, numerous studies are published each year presenting novel biomaterials and therapies with purported improvements over existing regenerative treatments. Few of these approaches are tested in vivo. Fewer still report on key outcomes that indicate full periodontal tissue regeneration. While in vitro studies are important for determining cytocompatibility and possible bioactivity, the complex nature of periodontal tissues and wound healing mean that promising benchtop materials may not perform well within standardized animal models, let alone in clinically relevant defects.

The purpose of this review is to describe key principles of periodontal wound healing and regeneration that can inform the design and testing of new engineered therapies. Insights can also be gleaned from periodontal development and the structures of mature periodontal tissues, both of which have been reviewed elsewhere (10-12). Pre-clinical studies of engineered biomaterials for periodontal regeneration are also highlighted to illustrate advances in the field thus far.

\section{PERIODONTAL WOUND HEALING AND GUIDED TISSUE REGENERATION}

The tooth root represents an anatomic challenge for formation of new cementum with associated PDL fibers that also connect to alveolar bone. Early attempts in periodontal tissue regeneration utilized autologous bone grafts, showing new bone formation could occur in periodontal defects when grafting was coupled with careful surgical techniques and strict patient maintenance $(13,14)$. Despite this promise, studies also showed that regeneration of the periodontal attachment did not always accompany bone growth, as downgrowth of epithelium between the root surface and new bone could occur rather than formation of new cementum and an interposed PDL $(15,16)$.

Both root dentin and cementum are avascular and contain few cells, while PDL, gingival connective tissue, epithelium, and alveolar bone each contain large populations of cells with proliferative capacity (17). Early work with these cell populations led to the hypothesis that the cell type which first reached the root surface during wound healing would dictate the nature of the new tissue that formed (18). In this case, a therapeutic approach which promoted selective cell repopulation of wounds by cells from both PDL and bone, rather than bone alone, or gingival connective or epithelial tissue, would promote periodontal tissue regeneration. Cells in the $\mathrm{PDL}$, in particular, were considered to have osteogenic, fibrogenic, and cementogenic potential, suggesting that their presence would be required for formation of a functional periodontal attachment (18). This hypothesis was tested in a series of studies using extracted tooth roots, where the root surface was either debrided of all soft tissues and cementum or the cementum and PDL was left intact. When transplanted into bone, roots with existing PDL showed formation of a layer of new cementum over the old cementum surface together with new PDL fibers inserting into cementum and bone, while root surfaces where PDL was removed underwent resorption or became ankylosed to host bone (19). When teeth were transplanted into gingival connective tissue, root surfaces with existing PDL also formed new cementum and PDL fibers, while unattached gingival tissue grew adjacent to roots without PDL (20). Critically, new cementum and PDL could form on root surfaces previously affected by periodontitis if the roots remained submerged beneath the gingiva (21). However, if roots became exposed to the oral cavity, downgrowth of epithelial tissue occurred and subsequently less new cementum and PDL formed (21). In summary, these studies suggested that cells from either alveolar bone or gingival connective tissue could not form new cementum and PDL, but that cells in the PDL could form these tissues, even the PDL from teeth previously affected by periodontitis. Furthermore, rapidly proliferating gingival epithelial or connective tissue cells, if not excluded from the root surface, would interfere with the regenerative process mediated by the PDL.

These studies led to the development of guided tissue regeneration (GTR) as a treatment approach for restoring a functional periodontal attachment. Initial studies in animals (22-24) and humans $(25,26)$ used thin, cell occlusive barrier membranes secured around the roots of teeth to allow migration of cells from bone and PDL into defects while preventing epithelial downgrowth and gingival connective tissue from contacting the root (Figure 2). While these GTR barriers promoted formation of new cementum, PDL, and bone, complete periodontal tissue regeneration was inconsistent. Bone formation did not always parallel formation of cementum and PDL (27), and new cementum was often the cellular subtype rather than the acellular form typically associated with inserting PDL fibers $(24,28)$. The regenerative capacity of remaining bone and PDL in large periodontal defects and the surface characteristics of periodontitis-affected roots were considered as possible factors limiting GTR outcomes (29). Further studies showed that defect configuration, surgical factors, and barrier design also played a critical role in determining the extent of guided periodontal tissue regeneration.

During periodontitis, bacteria and endotoxin infiltrate tooth root surfaces. Mechanical removal of the affected root surface leaves a layer of mineralized, amorphous debris (smear layer) with mechanical and biochemical properties unfavorable for periodontal cell attachment (30). Application of acids or 
A

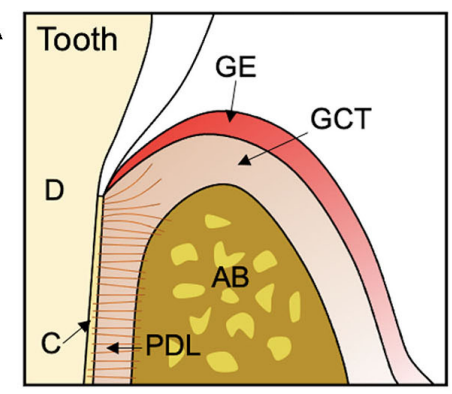

B

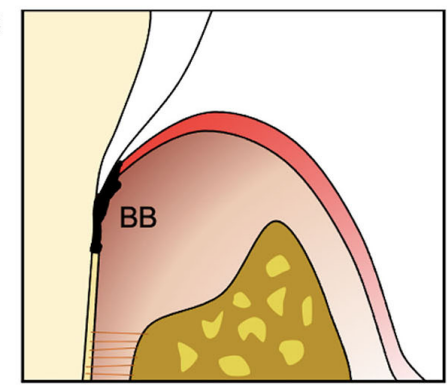

C

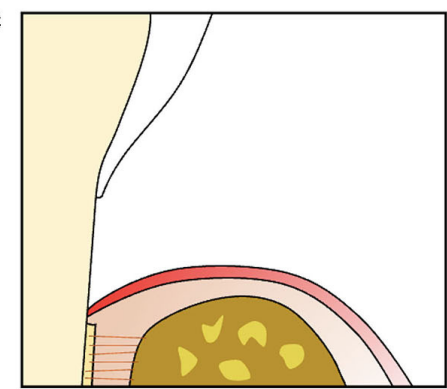

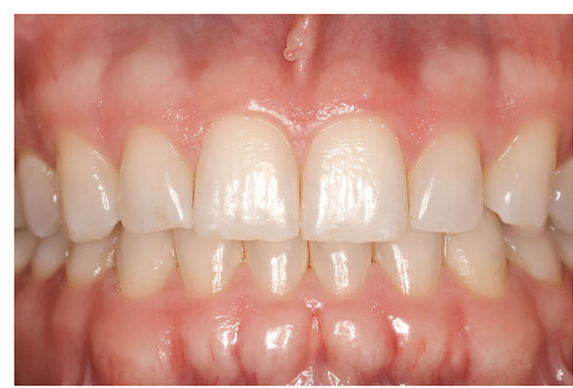
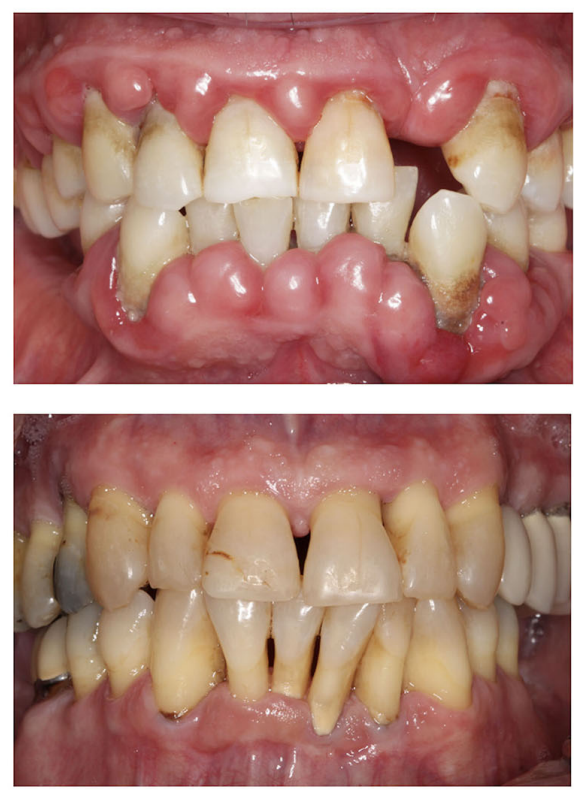

FIGURE 1 | Cross-section illustrations and representative photographs of the teeth and periodontal tissues in (A) health, (B) periodontitis, and (C) after resective surgery. (A) The healthy periodontal tissues consist of cementum (C) lining the dentin (D) of the tooth root, the alveolar bone (AB), and the interposed periodontal ligament (PDL) which supports the overlying gingival connective tissue (GCT) and epithelium (GE). (B) Periodontitis is characterized by a destructive inflammatory response to bacterial biofilms (BB) on the tooth and tooth root surface that damages and destroys the periodontal tissues. (C) Therapies that remove the bacterial biofilm and affected tissues leave teeth exposed to the oral cavity and with reduced biomechanical support.

chelating agents to the root surface smear layer exposes dentin collagen fibrils which may facilitate periodontal ligament cell attachment and subsequent formation of cementum and PDL (31). However, animal studies indicated that root surface demineralization played a key role at an earlier stage of healing, promoting wound stability through linkage of the fibrin clot to exposed collagen fibrils on the root surface and inhibiting epithelial downgrowth (32). Despite this promise, clinical studies using root demineralization showed mixed results (33). While root surface modification appears to improve early matrix protein and cell adhesion, this treatment alone may not provide sufficient wound stability to inhibit epithelial downgrowth while supporting migration of periodontal progenitor cells, a role for which GTR barriers are well suited (34). This was confirmed in additional studies showing no benefit of root demineralization when PDL cells were absent $(35,36)$. Demineralized roots lacking epithelial downgrowth were also frequently affected with root resorption and ankylosis (37), which may have been a consequence of gingival connective tissue or bone-derived cells reaching the root surface instead of cells from the PDL (38).
The principles underlying successful GTR have been extensively explored in the canine supraalveolar periodontal defect model, where defined defects are created surgically and little spontaneous tissue regeneration occurs (39). Placement of barriers over these defects inhibited epithelial downgrowth and promoted bone formation, but these two outcomes were not necessarily associated with formation of new cementum with inserting PDL fibers $(40,41)$. The condition of the root surface under the GTR barrier also affected tissue formation, as heparin-treated roots supported less tissue regeneration, likely due to poor attachment of the initial fibrin clot and subsequent loss of wound stability (40). Preventing gingival connective tissue infiltration, in particular, appeared necessary for maximal new cementum formation (42). In contrast, using non-occlusive barriers with $300 \mu \mathrm{m}$ pores led to increased soft tissue stability and reduced incidence of barrier exposure at the expense of new bone and cementum formation (42) Functionally oriented PDL could form between new cementum and bone without opposing occlusal forces, as opposing teeth were removed or reduced in height and animals fed a soft $\operatorname{diet}(42,43)$. 
TABLE 1 | Current and emerging approaches for periodontal tissue regeneration.

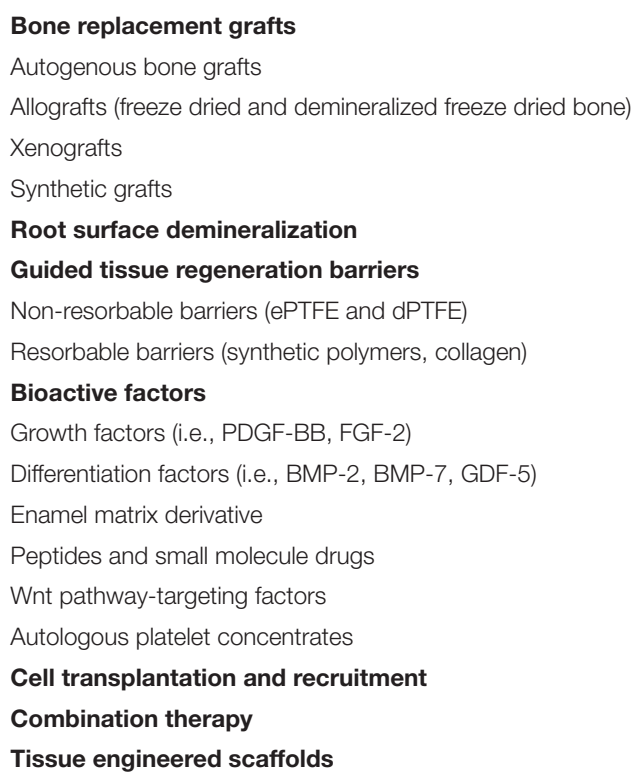

Root surface demineralization

Guided tissue regeneration barriers

Non-resorbable barriers (ePTFE and dPTFE)

Resorbable barriers (synthetic polymers, collagen)

Bioactive factors

Growth factors (i.e., PDGF-BB, FGF-2)

Differentiation factors (i.e., BMP-2, BMP-7, GDF-5)

Enamel matrix derivative

Peptides and small molecule drugs

Wnt pathway-targeting factors

Autologous platelet concentrates

Cell transplantation and recruitment

Combination therapy

Tissue engineered scaffolds

ePTFE, expanded polytetrafluoroethylene; dPTFE, dense polytetrafluoroethylene; PDGF, platelet derived growth factor; FGF, fibroblast growth factor; BMP, bone morphogenetic protein; GDF, growth/differentiation factor.

The architecture of periodontal defects has long been recognized as an important predictor of the healing response. For autologous bone grafts, the predictability of tissue regeneration was tied to the configuration of the periodontal defect: bone fill increased as the surface area of the surrounding bony walls increased, while an increased surface area of the exposed root negatively affected bone formation (44). In contrast, in the supra-alveolar defect model, extensive regeneration could occur in the absence of supporting bony walls as long space maintenance was provided by stable GTR barriers (45). However, when barriers were compressed or displaced, the extent of tissue regeneration was directly associated with the wound area maintained under the barrier (43). In clinical practice, defect configuration is still likely to influence GTR outcomes. Unless using a stiff self-supporting barrier, such as titanium-reinforced ePTFE, barrier stability and subsequent space maintenance will rely on the residual bony walls or the presence of materials such as particulate bone grafts underneath the barrier (46). Studies in the supra-alveolar defect model also showed that placement of slowly or non-resorbing biomaterials underneath GTR barriers could limit the volume of new bone growth (47), further highlighting the challenges inherent in using biomaterials to direct periodontal wound healing.

The supraalveolar defect model has also been used to identify the temporal contributions of cells in the residual PDL and alveolar bone during GTR (48). During the first 2 weeks of healing, cells migrated from both tissues into the wound space to form provisional tissue matrices of both bone and PDL. By 4 weeks, the framework of new tissues was established and had begun to mature. Cells from the PDL appeared responsible for both new cementum and PDL formation, and alveolar bonederived cells formed the bulk of new bone. However, the limited labeling techniques available in this large animal model meant that the contribution of PDL cells to regenerated bone or the role alveolar bone cells in new cementum and PDL formation was still unclear (48). Earlier studies using ${ }^{3} \mathrm{H}$-thymidine $(49,50)$ or bromodeoxyuridine (BrdU) (51) labeling in large animal wounds also observed migration of proliferating cells from residual PDL and bone into protected wound spaces. In these studies, resident cells in only a small portion of the PDL adjacent to the wound were activated, and once in the defect, proliferating cells derived from PDL or bone could not be distinguished from each other.

A similar sequence of wound healing events was also found during GTR at naturally occurring periodontal defects $(52,53)$. Initially, wounds consisted of fibronectin and vitronectin-rich granulation tissue, with bands of collagen type I forming at bone and tooth surfaces by 2 weeks. Provisional tissues with increased collagen types I and III content were present by 4 weeks. New cementum formation began at the margins of residual PDL and occurred independent of bone formation. New bone formed in distinct regions, first along the root surface and then later within the residual bone defect, suggesting both PDL and bone cells contributed to new bone formation. Initially, new collagen fibers in the PDL region were disorganized or parallel to the tooth, disconnected from perpendicularly inserting fibers at the periphery of new cementum and bone. While the bulk of new tissues were formed by 4 weeks, longer healing times were required for maturation of a fully organized PDL.

Altogether, these studies highlight the importance of wound stability and space maintenance during the critical early healing period. The volume of newly formed tissues is established within this 4-6 week period, and tissues continue to mature thereafter, a finding confirmed by other studies in large animal models (5456). Exposure of barriers to the oral cavity, possibly due in part to poor integration with overlying gingival tissue and limited vascularization, leads to rapid bacterial colonization of the barrier and an intense host inflammatory reaction which limits tissue regeneration (57).

Wound stability and space maintenance is critical for inhibiting epithelial downgrowth and allowing repopulation of the root surface and periodontal defect by cells from the PDL and bone which then form new periodontal tissues. Cell differentiation, proliferation, and migration is clearly required for resident periodontal cells to accomplish this task. Thus, identifying the location and characteristics of progenitor cells in the PDL which supply cementoblasts, fibroblasts, and osteoblasts is an important and longstanding challenge.

\section{PERIODONTAL PROGENITOR CELLS}

Early studies in mice characterized PDL cell behavior using uptake of ${ }^{3} \mathrm{H}$-thymidine to track cell division and migration (58). A slowly dividing cell population with progenitor-like behavior was identified adjacent to PDL blood vessels, activating following injury to proliferate and migrate into periodontal wounds (59). In healthy periodontal tissues, these slowly dividing cells also provided a source of cells that proliferated and migrated within the PDL toward cementum and bone $(60,61)$. Cell movement 
A

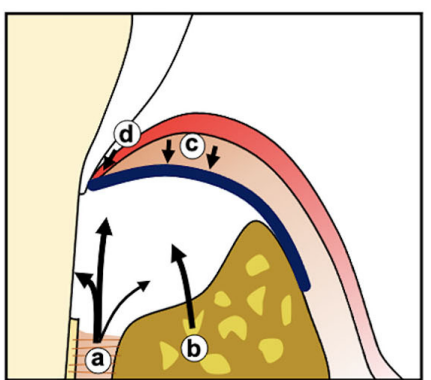

B

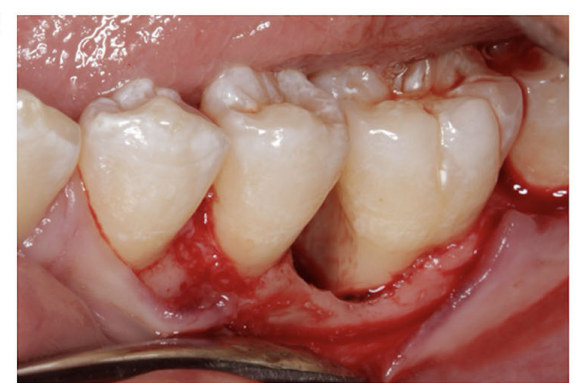

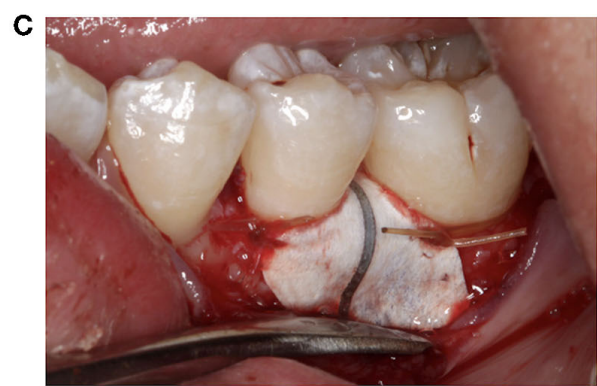

FIGURE 2 | (A) Illustration of guided tissue regeneration with a barrier membrane (blue line) which allows cells from the PDL (a) and alveolar bone (b) to fill the wound space while excluding cells from the gingival connective tissue (c) and gingival epithelium (d). (B) Clinical photographs of a periodontal defect after reflection of the gingiva and debridement of the bone defect and root surface, and (C) after placement of a titanium-reinforced expanded polytetrafluoroethylene (ePTFE) guided tissue regeneration barrier.

also occurred from vascular channels in the alveolar bone into the PDL, indicating either an additional source of periodontal progenitor cells in the alveolar bone or the presence of an open system encompassing both PDL and bone (62). Later studies showed that the PDL perivascular region contained cells positive for STRO-1 and CD146, markers for pericyte stem/progenitor cells in other mesenchymal tissues (63). Cells isolated using these markers and cultured in vitro were shown to have stem cell properties, including the ability to form PDL and cementum-like tissues when implanted in vivo (64).

The development of mouse genetic models and advanced labeling techniques has allowed improved tracking of periodontal cell populations and enabled progress in distinguishing between periodontal progenitors and their differentiated progeny through lineage tracing. Alpha-smooth muscle actin ( $\alpha$ SMA), a marker for perivascular cells in multiple tissues, was used to trace PDL cells within transgenic mice where mature osteoblasts and cementoblasts or PDL fibroblasts were also labeled with separate markers (65). During normal growth and development, $\alpha S M A$ lineage PDL cells migrated from their perivascular location in the PDL and differentiated into osteoblasts, cementoblasts, and PDL fibroblasts. After injury, $\alpha S M A$-lineage cells in the PDL and gingiva also proliferated and differentiated to form new periodontal tissues. While useful for tracking this PDL cell sub-populations, $\alpha S M A$ labeling was limited by marking additional cells, including myofibroblasts and cells in the gingival connective tissue, and may not have labeled quiescent progenitor cell populations $(65,66)$.

A recent study identified a PDL progenitor cell population concentrated around neurovascular bundles in the apical PDL of mouse molars characterized by expression of Gli1, a target of the Sonic hedgehog signaling pathway (67). During tissue homeostasis, progeny of Gli1-expressing PDL cells proliferated and migrated throughout the periodontal tissues, acting as the source for the vast majority of cementoblasts, osteocytes, and PDL fibroblasts (Figure 3), mirroring a similar observation published decades earlier that showed a highly proliferative cell population in the apical PDL which migrated coronally through the PDL (68). In contrast, expanding $\alpha S M A$-lineage cells contributed to only a small percentage of periodontal cells during homeostasis and were also labeled as a Gli1-lineage population, suggesting they were a subset of Gli1-positive progenitor cells. NG2, PDGR $\alpha$, and LepR lineage cells, populations identified as progenitors in other tissues, had far less contribution to periodontal cell turnover and were also marked as Gli1-lineage cells. After periodontal injury, Gli1-lineage cells rapidly expanded to provide the majority of PDL fibroblasts and osteoblasts which formed new tissues. A further study clarified that while the number of Gli1-expressing progenitor cells decreased over time in mouse molar PDL, their progeny progressively increased near sites of active cementum formation (69). These Gli1-lineage cells were responsive to Wnt signaling, decreasing in number when $\beta$-catenin was deleted and increasing in number when $\beta$-catenin was constitutively activated or when sclerostin antibody, a Wnt pathway agonist, was applied. These increases or decreases in Gli1-lineage cell numbers were accompanied by an increase or decrease in cementum formation.

Lineage tracing has also been used to investigate the osteogenic potential of periodontal cell populations in tooth extraction sites. Wnt-responsive cells, indicated by expression of Axin2, were present in small numbers in healthy periodontal tissues $(70,71)$. After tooth extraction, Axin2-lineage cells that remained in the residual PDL proliferated and migrated into the socket. Later, once the socket was filled with mineralized tissue, Axin2-lineage cells were present in the bone matrix and expressed osteoblast markers. Transplanting tooth roots with residual PDL from green fluorescent protein (GFP)-labeled mice into bone defects in non-GFP mice also resulted in new bone formation by GFP-positive osteoblasts (70). This finding confirms previous work where transplanted molars from GFPtransgenic rats formed new bone in subcutaneous tissue of nonGFP rats $(72,73)$. A recent study also transplanted molars from Gli1-transgenic mice to wild type mouse subcutaneous tissue and observed the generation of Gli1-lineage osteoblasts and osteocytes from PDL tissue (74).

Emerging techniques may better distinguish between different PDL cell populations and their roles in wound healing. Single cell RNA sequencing (scRNA-seq) of mouse PDL cell populations identified mature cells with a fibroblast or mineralized tissue signature together with intermediate and 

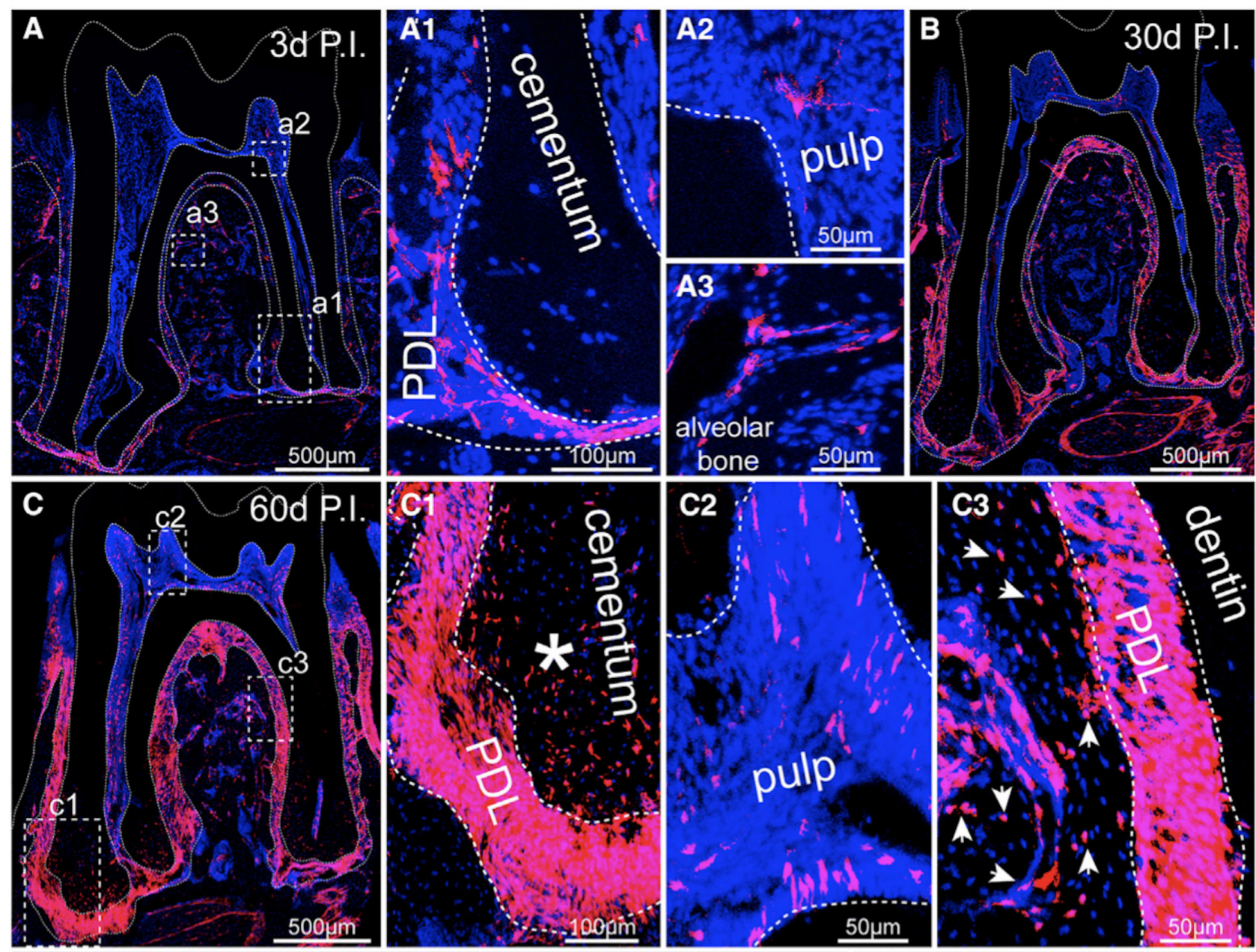

FIGURE 3 | (A) Cross-section of a mouse mandibular molar 3 days post injection (P.I.) of tamoxifen which labeled all progeny of Gli1-expressing cells (Gli-1-lineage) with fluorescent marker tdTomato (red). All cell nuclei are stained blue with DAPI. (A1) An inset from (A) showing some Gli-1-lineage cells present in the apical PDL. (A2, A3) Few cells Gli-1-lineage cells were labeled in the pulp (A2) and alveolar bone (A3). (B) By 30 days P.I., Gli1-lineage cells were present throughout the PDL. (C) At 60 days P.I., the majority of PDL cells and cementocytes (C1) and many osteocytes (C3) were Gli1-lineage, while few dental pulp cells were labeled (C2). Figure reproduced with permission from (67).

progenitor cell populations (75). CD90 (Thy1), a common marker for mesenchymal stem cells, was highly expressed in progenitor cells, while Axin2-lineage cells were found within both differentiated and progenitor cell populations. Labeling in mice confirmed that Axin2-lineage cells actively formed cementum, PDL, and bone during both tooth development and homeostasis. In contrast, CD90-expressing cells were active only during development and decreased in number over time. Mechanical stimulation of periodontal tissues could reactivate CD90-lineage cells but combined inflammatory and mechanical stimulus inhibited their activity.

In summary, recent studies have confirmed the presence of progenitor cell populations in the mature PDL which differentiate to supply osteoblasts, fibroblasts, and cementoblasts during both periodontal homeostasis and wound healing. Challenges remain in finding a true PDL stem cell in the mature
PDL or identifying all PDL progenitor cell subpopulations and distinguishing these progenitors from their progeny. Currently, no marker can differentiate between cementoblasts and osteoblasts, or between cementoblasts that form different cementum subtypes. The contributions of progenitor cell populations in alveolar bone and gingival tissue to periodontal wound healing are also unclear. Endogenous cell labeling is limited in larger animal models in which GTR, growth factors, or tissue engineered scaffolds can be tested in more clinically relevant periodontal defects. Thus, much is still unknown on how progenitor cells in residual periodontal tissues interact with or can be targeted with engineered therapies.

Moving forward, critical questions should guide the development of new therapeutic approaches for periodontal tissue regeneration. Can new GTR barriers be designed to better take advantage of the endogenous wound healing potential of 
periodontal cell populations while providing space maintenance and wound stability? Which signaling factors mediate activation and differentiation of periodontal progenitor cells and how can they be harnessed for clinical periodontal regeneration? Will tissue engineered scaffolds enhance or impede the regenerative capacity of residual periodontal tissues?

\section{ENGINEERING BARRIERS FOR ENHANCED GUIDED TISSUE REGENERATION}

GTR remains a viable clinical strategy with documented longterm success (76). Studies also show GTR leads to improved tooth survival, reduced periodontal disease recurrence, and lower overall treatment costs (5). However, GTR with current barrier membranes is technically demanding and suffers from frequent post-operative complications, outcomes which may be associated with barrier material properties (77). Expanded polytetrafluoroethylene (ePTFE) is the most studied GTR barrier material, with over 30 years of clinical use (25). ePTFE barriers are generally biocompatible, eliciting a mild foreign body reaction that is similar to collagen barriers $(78,79)$. However, any exposure of ePTFE to the oral cavity results in rapid bacterial colonization of the porous barrier surface. Dense PTFE barriers (dPTFE), which contain submicron pores on an otherwise smooth surface, are less susceptible to biofilm formation upon exposure (80), but may not provide the same wound stability, as overlying tissues show minimal adhesion (81). Non-resorbing PTFE barriers also require an additional surgical procedure for removal of the barrier, typically performed 4-6 weeks after initial placement. The volume of tissue formed during these first weeks of healing is a significant predictor of long-term tissue regeneration $(46,82)$, emphasizing the brief, but critical timeframe where space maintenance and wound stability is required for optimal GTR outcomes.

Resorbable barriers eliminate the need for a second surgical procedure and have generally shown similar clinical outcomes to ePTFE barriers (83). Barrier dissolution and subsequent wound epithelialization after exposure to the oral cavity also minimizes bacterial colonization (84). Collagen barriers have attractive properties, supporting host cell binding, integrating into periodontal tissues, and allowing vascular infiltration $(84,85)$. The stiffness and degradability of collagen-based barriers can be tuned by crosslinking collagen fibers to create a slower degrading material with improved mechanical properties (86). While crosslinked collagen barriers may have improved space maintenance and barrier capabilities, they can also produce a greater foreign body reaction and exhibit delayed barrier vascularization and tissue integration $(87,88)$. Synthetic polymer barriers have also been widely investigated and are typically composed of aliphatic polyesters to produce various degradation profiles (89). Some resorbable polymer barriers can elicit a significant foreign body reaction (90), and degradation products can also result in a localized inflammatory response (91). Nevertheless, both synthetic and crosslinked collagen barriers are generally biocompatible and can maintain barrier function for extended periods of time $(92,93)$. However, any clinical benefit for active barrier function beyond 6 weeks is uncertain, as long-term retention of biomaterials at periodontal defects could interfere with periodontal tissue remodeling and maturation (94).

Most resorbable barriers lack mechanical properties that would ensure space maintenance at large, non-contained periodontal defects. Thus, particulate grafts are widely used in conjunction with these barriers to improve barrier stability (95). Grafts with osteoconductive properties may support bone formation and indirectly promote new cementum and PDL formation through improved wound stability. However, grafting materials can also interfere with migration and provisional tissue formation from remaining cells in the PDL and bone, hindering tissue regeneration $(47,94)$.

A wide variety of engineered barriers have been investigated for periodontal GTR. Significant challenges remain in identifying a biomaterial which is stiff enough to provide space maintenance yet is adaptable to a wide range of defects and resorbs in the appropriate time frame with a minimal inflammatory reaction (96). An additional challenge which has received far less attention is barrier-soft tissue integration. Maintaining an epithelial seal at the junction of the barrier and the tooth surface as well gingival tissue coverage during healing, all while allowing periodontal tissues formation underneath, is a complex task for a single biomaterial. Many experimental barriers with a wide range of physical properties and biologic functionalization have been tested with in vitro assays [refer to reviews (93, 96, 97)]. Fewer novel barrier materials have undergone in vivo testing, possibly due to the financial and regulatory challenges of utilizing large animal models to create appropriate periodontal defects.

A notable example of a rationally designed barrier with in vivo testing was a bi-layered barrier with a porous calcium scaffold undersurface to promote clot retention and enhance wound stability (98). Polylactic-co-glycolic acid (PLGA) was combined with calcium phosphate $(\mathrm{CaP})$ to create a moldable, degradable biomaterial with the porous layer facing the tooth roots and a flat, smooth outer layer serving as a barrier against gingival cell infiltration. This barrier alone was sufficient to promote functional periodontal regeneration in canine periodontal defects together with restoration of large bone volumes, a finding attributed to the sufficiently stiff, space-maintaining nature of the barrier. The micro/nano-topography of the CaP-coated macroporous inner surface may also have promoted cell and clot adhesion while providing space for new tissue formation, maximizing the host regenerative potential.

A similar barrier composed of polyhydroxybutyrate and hydroxyapatite (HAp) was designed to provide a stiff but degradable barrier with an inner porous surface (99) (Figure 4). However, gingival recession and barrier exposure occurred early on during the healing process and minimal periodontal tissues were formed under the barrier. This barrier material may have not supported adhesion of overlaying gingival tissues, leading to soft tissue recession and barrier exposure. Furthermore, this barrier was too stiff to mold to the teeth and defect, so exposure 
A
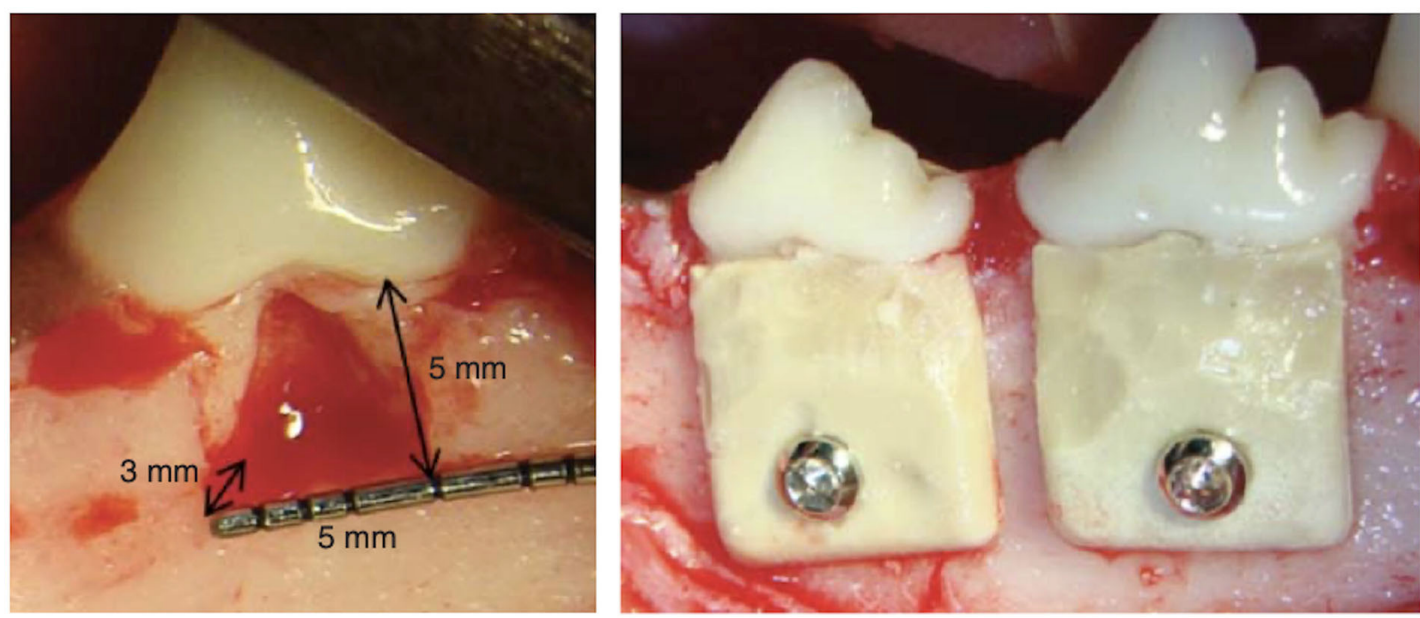

B
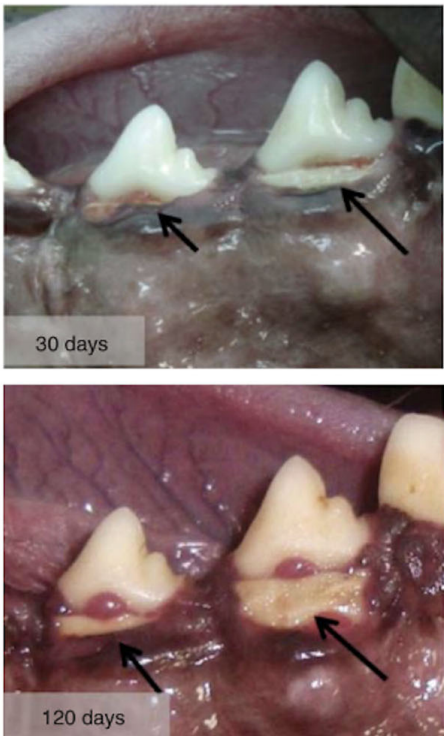

C

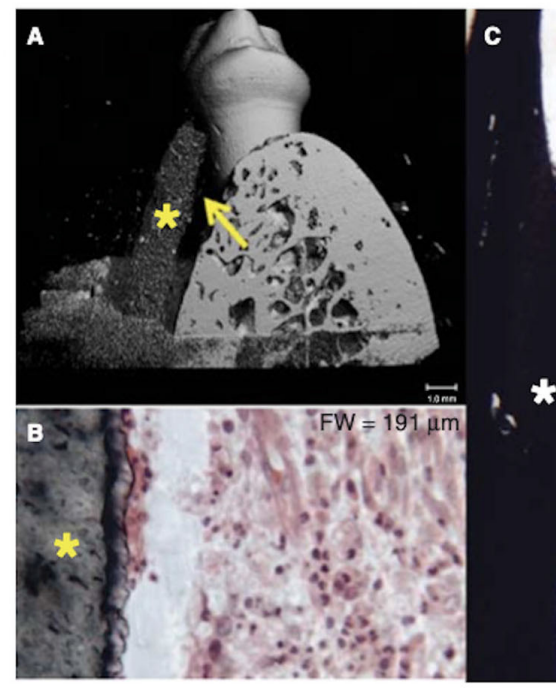

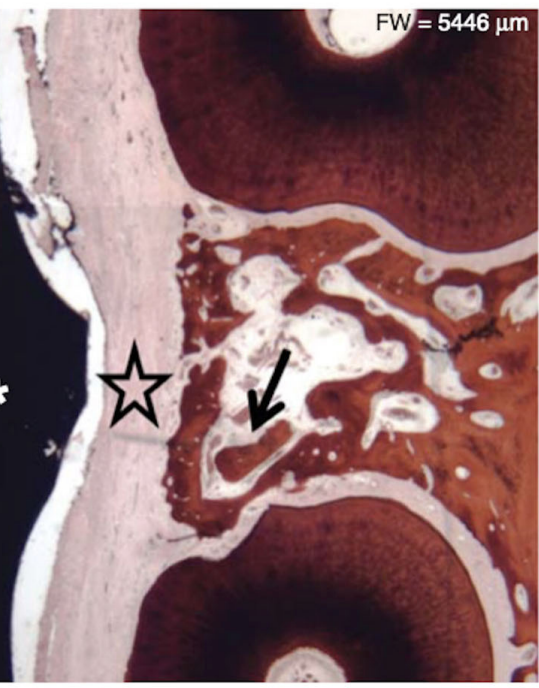

FIGURE 4 | (A) Furcation defects were created at canine molars and rigid polyhydroxybutyrate and hydroxyapatite barriers were placed and secured. (B) Barrier exposure and progressive gingival recession was present after 30 and 120 days of healing. (C) (A) Micro-computed tomography image shows the barrier (*) resting against the tooth root with an empty space between (arrow). (B) Dense inflammatory cell infiltrate was present in the connective tissue adjacent to the barrier $\left(^{\star}\right)$. (C) Connective tissue (large star) occupied the space between the barrier (*) and regenerated bone (arrow). Figure adapted with permission from (99).

of the barrier border may have led to bacterial infiltration and inflammation in the wound space.

Electrospinning has been widely investigated as a method for fabricating barrier membranes, providing enhanced control of barrier composition and microstructure. Fibrous electrospun mats mimic key extracellular matrix (ECM) physical characteristics that direct cell activity, and electrospun fibers can be used to load antibiotics, growth factors, or small molecule drugs for release via fiber surface degradation or from within hollow fibers $(100,101)$. A wide variety of electrospun barrier have been developed and tested in vitro [see reviews $(96,102)]$. However, in vitro results showing topographical cell guidance or barrier-mediated cell differentiation may have limited clinical potential, as these functions seem to play a minor role in the clinical success of GTR barriers.

One electrospun barrier, composed of poly (lactic acid) (PLA) and $\beta$-tricalcium phosphate $(\beta$-TCP) dip-coated in poly (ethylene oxide) to increase hydrophilicity, was recently developed and tested as a GTR barrier in both a porcine animal model and in a clinical trial (103). The electrospun barrier was able to provide space maintenance and promoted new bone and cementum formation in the animal defect. In the clinical study, the novel barrier performed to a similar level as a commercially available PLA barrier with no incidence of barrier exposure, suggesting that the hydrophilic barrier surface may have promoted connective tissue cell attachment and subsequent tissue stability. 
Improved barriers alone may not be able to fully overcome the limitations of GTR. Even with optimal space maintenance and wound stability, wound repopulation and differentiation of bone and PDL progenitor cells may be limited by the distance between residual tissues and the barrier surface. Additionally, host cells may be unable to recreate oriented periodontal tissues in large defects without additional guidance. Thus, delivery of biologic factors for cell recruitment and differentiation or cell delivery have been extensively explored. Scaffolds that fill the space of the periodontal defect to provide physical guidance have also been intensively investigated. The functional periodontal attachment is extraordinarily complex. Accordingly, scaffold-based tissue engineering strategies for restoring these tissues have increased in complexity, with the premise that controlling more of the individual biologic processes occurring during tissue regeneration will improve the predictability of regenerative treatments.

\section{PERIODONTAL GROWTH FACTORS AND BIOACTIVE SUBSTANCES}

\section{Growth Factors in Periodontal Wound Healing}

Amplifying or targeting the cells and signaling factors which drive periodontal cell proliferation, migration, and differentiation is an attractive strategy for promoting tissue regeneration. Soluble factors stored within the extracellular matrix of PDL, cementum, and bone are released during periodontal wound healing. Paracrine signaling between local and infiltrating cells and periodontal progenitor cells also occurs, altering the course of tissue regeneration. Growth factors mobilize and promote the proliferation and differentiation of host cell populations in the PDL and bone. Other compounds and small molecule drugs can target key cells or pathways to improve healing.

Soluble factors released during the initial stages of wound healing, such platelet derived growth factors (PDGF), transforming growth factor- $\beta$ (TGF- $\beta$ ), fibroblast growth factors (FGF), epidermal growth factor (EGF), and insulin-like growth factors (IGF), are thought to induce PDL cell migration, proliferation, and ECM protein synthesis (104, 105). Despite numerous studies applying these factors in periodontal defects, little is known about their temporal expression and relative roles in driving key in vivo periodontal events. In mature periodontal tissues, fibroblasts, cementoblasts and osteoblasts express TGF- $\beta 1$ and TGF- $\beta$ receptors TGF $\beta$ R-II and -III and $(106,107)$. Growth factor receptors PDGF-R $\beta$, TGF- $\beta$ RI, and TGF- $\beta$ RII are expressed strongly in regenerating tissues found underneath GTR barriers (108). PDGF-R $\beta$ and PDGF-A and -B chains are also expressed during early wound healing of gingival connective tissue and diminish by the time granulation tissue has replaced the fibrin clot at 7 days (109). Basic FGF (bFGF or FGF-2) is secreted by PDL cells and endothelial cells in both healthy and diseased PDL tissues (110) but this expression may decrease with age (111). PDL cells also express IGF1 receptor (IGF1R), and IGF-I, -II, and IGF binding proteins
(IGFBPs) are present in the PDL and cementum, with strong expression at the PDL-cementum interface (112). IGF-I and -II localization in the PDL and IGF1R expression in PDL cells and cementoblasts also increases during root and bone resorption and the subsequent repair process occurring during orthodontic tooth movement (113).

Bone morphogenetic proteins (BMPs), members of the TGF- $\beta$ superfamily, are powerful inducers of cellular differentiation. Multiple BMPs play complex, complementary roles during periodontal development $(114,115)$. Intact PDL tissue contains BMP-2 and-4 (116), and BMP-2,-4 and-7 are present adjacent to and within newly formed cementum, PDL and bone in regenerating periodontal defects $(117,118)$. However, the signaling activity of specific BMPs during endogenous periodontal tissue regeneration is still unclear. Furthermore, application of recombinant BMPs is likely to induce differentiation of cells not already committed to periodontal repair, rather than providing a favorable environment for differentiated periodontal cells to form new tissues (119). The ability of BMP-2 to promote significant bone formation in periodontal defects is well established $(120,121)$. On the other hand, cementogenesis does not necessarily parallel BMP-2-mediated bone formation and BMP-2 application can increase the incidence of ankylosis and root resorption in some large animal models (122-124). In supra-alveolar periodontal defects, BMP-2 delivery together with macroporous PTFE or resorbable synthetic barriers was more effective in regenerating bone vs. barriers without BMP-2 $(125,126)$. However, ankylosis was more common with BMP-2 administration, and new cementum formation was not further increased vs. GTR and was not associated with new inserting PDL fibers. BMP-7 (osteogenic protein-1, OP-1) has been shown by some investigators to be more cementogenic than BMP-2 $(127,128)$ and other members of the BMP family have shown ability to promote periodontal tissue regeneration, including BMP-3 (osteogenin), BMP-6, BMP-12, and growth/differentiation factor-5 (BMP-14) (129-132).

Numerous studies have shown the benefits of single growth factor administration in promoting periodontal wound healing $(133,134)$. PDGF-BB, PDGF-BB with IGF-1, FGF-2, and GDF-5 have reached clinical trials [see reviews (135-137)], and rhPDGF$\mathrm{BB}$ with a $\beta$-TCP particle carrier is currently FDA approved for use in periodontal defects ${ }^{1}$. A recent phase III trial compared FGF-2 to enamel matrix derivative (EMD), with greater bone formation at sites treated with FGF-2 (138). Combining a growth factor with potent mitogenic properties such as PDGF with a $\mathrm{BMP}$ is an attractive approach for coordinating cell recruitment and proliferation with differentiation. Studies in bone healing demonstrate that combinations PDGFs, TGF- $\beta$ s, FGFs or IGFs with BMPs can have additive, synergistic, or even inhibitory effects based on the time of application, dosage, or anatomic site (139). The coupling of angiogenic (i.e. vascular endothelial growth factor-VEGF) and osteoinductive factors to promote bone formation has also been extensively explored (140) and is an emerging approach in periodontal tissue regeneration. ${ }^{1}$ https://www.accessdata.fda.gov/scripts/cdrh/cfdocs/cfpma/pma.cfm?id=
P040013 


\section{Biomaterials for Controlled Growth Factor Delivery}

A key challenge for periodontal growth factor therapy is identifying temporal release profiles and combinatorial growth factor approaches to best control wound healing. Common hurdles facing soluble factor delivery in other tissues, such as high cost and significant side effects associated with supraphysiologic doses, are also relevant for periodontal tissue regeneration. A further challenge for signaling factor application in periodontal regeneration is coordinating retention and release while ensuring space maintenance and wound stability, a complex task which may be addressed by various engineered biomaterials.

Growth factors are typically dissolved in a liquid than mixed with particulate grafts, such as $\beta$-TCP or bone allografts, which provide a surface for growth factor adsorption and act as an osteoconductive, space-maintaining scaffold. However, growth factors show variable levels of adsorption to $\mathrm{CaP}$ and bone surfaces and exhibit a burst release behavior (141-143). This release profile may be beneficial for growth factors such as FGF2 and PDGF which appear to have their greatest impact during the initial stages of healing by stimulating cell recruitment and proliferation, but may be a less effective carrier for factors that target cellular differentiation. BMP-2 is typically delivered within an absorbable collagen sponge (ACS) which prolongs retention through BMP-collagen binding (144). However, the ACS has minimal space maintaining properties (145), and the large doses of BMP-2 required for biologic activity leads to significant portions of BMP-2 being immediately released from the ACS, resulting in BMP proteolysis and adverse side effects (146, 147). Studies in periodontal defects have indicated the BMP-2 retention and release differentially affects cementum and bone formation, with a fast release profile favoring bone formation while an extended release leading to improved cementum formation $(148,149)$, highlighting the unique challenges of periodontal bioactive factor delivery.

Various natural and synthetic materials have been tested for controlling localization and release of single growth factors in vivo. Controlled BMP-2 release in periodontal defects has been tested with various collagen or gelatin hydrogels (148, 149) and calcium phosphate particles (150). FGF-2 loading and release has been tested with heparin and porous $\alpha$-TCP particles (151) and gelatin sponges with $\beta$-TCP particles (152). Polymer microspheres have been used to load PDGF in the microsphere shell for early release and simvastatin the core to promote more sustained release (153). Microspheres composed of methacrylated dextran and gelatin have been tested for controlled release of IGF-I (154) or to deliver and release BMP-2 from gelatin hydrogels (155).

Early studies indicated that delivery of more than one growth factor did not necessarily lead to improved periodontal tissue regeneration. Application of IGF-I and/or PDGF-BB in periodontal defects showed that PDGF-BB alone, but not IGFI, promoted new bone, cementum and PDL formation (156). Combined delivery of both growth factors led to non-significant increases in new tissue formation, pointing to the possibility of a synergistic effect when more than one growth factor was applied. Dual delivery of BMP-2 and BMP-7 to furcation defects, building on the osteoinductive properties of the former and cementogenic effects of the later, was tested in furcation defects (128). However, combined application led to less bone and cementum formation compared with delivery of either BMP alone.

Tailored polymer and $\mathrm{CaP}$ materials may afford increased control over multiple factor release to further improve wound healing. PLA-PLGA microspheres loaded with simvastatin and/or PDGF promoted significantly more new cementum when both factors were delivered together (153). Chitosan $\beta$-glycerophosphate hydrogel scaffolds were investigated for controlled delivery of BMP-7 with the antibiotic ornidazole, with results showing that scaffolds with BMP-7 led to more bone and cementum formation, with no apparent benefit for added ornidazole (157). Composite PLGA-PLLA electrospun meshes were engineered with a core-shell structure to provide shell loading of FGF-2 for burst release and BMP-2 loaded in the core for sustained delivery to fenestration defects (158). Meshes without growth factors showed similar healing outcomes as empty defects, while dual loaded scaffolds promoted host mesenchymal cell ingrowth and new bone, cementum, and PDL formation. In another study, BMP-2 or FGF-2 were suspended in a PGA solution and placed on root surfaces together with PLGA microparticle-CaP cement composite to fill the remainder of the periodontal defect (159). BMP-2 led to improved bone regeneration while FGF-2 administration led to new cementum and PDL formation and similar levels of bone formation as BMP-2. Combined BMP-2 and FGF-2 delivery was also tested in a large animal periodontal defect where BMP-2 was loaded into the cement composite and FGF-2 applied directly to the root surface (160). Defects treated with $\mathrm{CaP}$ cement and both growth factors showed similar volume of new bone compared to $\mathrm{CaP}$ cement alone, but dual growth factor delivery led to increased cementum and PDL formation and decreased epithelial downgrowth. Finally, a tri-layer chitin-PLGA hydrogel scaffold was designed to target each periodontal tissue: cementum (bioactive glass particles and rhCEMP1), PDL (FGF-2), and bone (bioactive glass particles and platelet rich plasma) (161). Early bone formation was similar in scaffolds with or without additional growth factors, but dense, mature bone was only present at later time points in the presence of growth factors. Similar cementum and PDL formation were described for all scaffolds, regardless of growth factor incorporation.

Combinations of other bioactive molecules and small molecule drugs have been tested for their ability to promote periodontal tissue regeneration. Porous PLA scaffolds were used for delivery of parthenolide, an anti-inflammatory drug, together with chitosan microspheres loaded with naringin, a flavonoid with osteogenic properties, with dual drug loaded scaffolds showing increased bone formation over unloaded scaffolds, while new cementum and PDL formation was not described (162). A tri-layer chitosan membrane was developed for rapid release of epigallocatechin-3-gallate, an anti-inflammatory compound, and sustained release of lovastatin to act as a controlled-release osteogenic drug (163). When used as a GTR barrier, the experimental barrier promoted increased bone formation in comparison to a collagen barrier, while both barriers led to similar cementum and PDL formation. 
A chitosan $\beta$-glycerophosphate hydrogel was used to load aspirin and erythropoietin to provide anti-inflammatory and angiogenic/osteogenic stimuli respectively (164). Application in an periodontitis model showed that combined delivery of both drugs prevented more alveolar bone loss than either drug alone.

Delivery of bioactive peptides and gene therapy can overcome difficulties with growth factor protein stability while allowing enhanced control over multiple factor localization and release. A polydopamine-apatite composite material with bioactive peptides derived from BMP-7 and/or VEGF was tested in fenestration defects (165). Both peptides together promoted more bone formation compared to either peptide alone, while cementum and PDL formation was not reported. Delivery of viral vectors or vector-transduced cells expressing single factors PDGF-B, BMP2, BMP-7, or FGF-2 in a variety of carriers have shown promise in promoting new bone and cementum formation (166-169). Mesoporous bioactive glass/silk was used to deliver PDGF-B and/or BMP-7 encoding adenoviruses (adPDGF-B and adBMP-7) to dehiscence defects (170). Scaffolds with adPDGF only demonstrated similar bone formation as empty scaffolds, while inclusion of adBMP-7 increased new bone volume. The height of newly regenerated periodontal tissues (new cementum and bone with interposed PDL) was greatest when both adPDGF-B and adBMP-7 were delivered to defects. Adenovirus vectors for PDGF and BMP-7 expression were also immobilized on PCL/PLGA scaffolds and promoted increased periodontal bone formation over scaffolds alone (171).

\section{Enamel Matrix Derivative (EMD)}

Purified enamel matrix proteins (EMPs), termed enamel matrix derivative (EMD), are a widely used biologic factor for clinical periodontal tissue regeneration. EMD is commercially available as a suspension of EMPs in propylene glycol alginate (PGA) (Emdogain $($ ) , a formulation which supports the precipitation and adherence of EMPs to the root surface during healing (172). The underlying rationale for the use of EMD is replicating events of periodontal development (173), a topic which has been extensively reviewed in other publications $(10,174)$. Briefly, EMPs are secreted by epithelial lineage cells (ameloblasts) during tooth formation. Hertwig's epithelial root sheath (HERS), a structure which directs root development through epithelialmesenchymal signaling (175), may also secrete EMPs or structurally similar proteins to direct cementum formation (173, 176).

The role of endogenous EMPs in periodontal wound healing is not well understood. Remnants of HERS, the epithelial rests of Malassez (ERM), are present in the PDL and are thought to help maintain PDL width by inhibiting dento-alveolar ankylosis and root resorption (175). In vivo, ERM cells may also retain the ability to secrete EMPs or EMP-like proteins $(177,178)$. While studies note a relationship between the presence of ERM and localized cementum repair (179), others have noted that periodontal tissue repair can occur independent of the number of ERM (180), and remodeled or regenerated PDL tissue may not contain ERM (181, 182). Regardless of its endogenous activity, EMP or EMD application promotes formation of new cementum and bone and has the ability to inhibit epithelial downgrowth and bacterial activity, improve angiogenesis, and alter immune cell signaling (183). Initial animal studies also showed the EMD promoted formation of acellular cementum, rather than the cellular form, in monkey dehiscence defects (184). However, human histologic studies have demonstrated formation of cellular cementum or a mix of acellular and cellular cementum after application of EMD, similar to that seen after GTR (185-187). While the exact mechanisms underlying EMD's bioactivity are still unclear, studies indicate that EMD may contain components with TGF- $\beta$ and BMP-like activity $(188,189)$ and can induce expression of these factors by periodontal cells (190-192) which may provide a plausible biologic mechanism for some of its biologic activities.

Application of EMD alone is typically relegated to wellcontained defects, as the viscous nature of the PGA carrier does not aid in space maintenance. Pre-clinical studies have shown that EMD was more effective in narrow vs. wide intrabony defects (193), and was inferior to GTR in Class III furcations (194, 195). A recent systematic review of clinical studies also found that defect morphology had a significant influence on clinical bone gain following regenerative therapies, including EMD application (196). The combination of EMD with various bone grafts has been widely explored as an approach to improve space maintenance and wound stability. Animal studies have shown an improvement in intrabony defect healing over EMD alone $(197,198)$, a finding confirmed by some systematic reviews of clinical studies $(199,200)$, but not others (201). Modifications to gingival flap design have also been investigated as a means to improve wound stability when applying EMD (202, 203). However, these approaches are only indicated for certain defects, with addition of bone grafts and/or barriers recommended when bony walls are absent (204).

Recent work has tested EMD in modified formulations and its interaction with various biomaterials in order to further improve regenerative outcomes. In vitro studies have examined the cellular effects of EMD loaded into hollow electrospun fibers (205) or adsorbed onto a decellularized dermal matrix (206) or collagen membranes (207). A liquid solution of EMD was recently developed which showed increased adsorption to bone graft particles vs. the PGA carrier (208). EMD protein retention on collagen sponges was also improved with the liquid suspension and its application supported greater bone and cementum formation in animal periodontal defects when compared to collagen sponges loaded with EMD in the PGA carrier $(209,210)$.

\section{Wnt Signaling}

The Wnt signaling pathway is an important regulator of tissue development and homeostasis (211). Canonical Wnt signaling is also required for the maintenance of mature periodontal tissues (212) with Wnt-responsive cells present in the PDL, alveolar bone, and cementum surface (213). Targeted deletion of Wnt signaling in mouse periodontal cells lead to loss of cementum and bone, widening of the PDL, and disorganization of PDL fibers (214). Overexpression of Wnt receptor LRP5 resulted in a narrowed PDL, while overexpression of Wnt inhibitor DKK1 led to a widened PDL, reduced cell proliferation, and loss 
of osteogenic markers in PDL cells (215). Knockout of Wnt inhibitor sclerostin also lead to thicker cementum and increased alveolar bone (216). During orthodontic tooth movement, Wnt activity was increased at sites of tension in the PDL where active bone formation is occurring, while DKK1 was elevated at sites of PDL compression and bone resorption (217). During repair of physiologic root resorption, sclerostin was present in the PDL adjacent to sites of active root resorption, and Wntresponsive PDL cells were responsible for depositing reparative cementum at resorption sites (218). When Wnt-responsive cells were eliminated in the PDL, extensive root resorption and loss of PDL fiber insertions occurred (218).

Active manipulation of Wnt signaling can promote periodontal wound healing, with injection of lithium chloride or anti-sclerostin antibodies at rat periodontal defects promoting new bone and cementum formation (219). Anti-sclerostin antibody loaded PLGA microspheres for sustained release have been applied to periodontal defect but did not improve bone formation vs. the systemically delivered antibody (220). In another study, lithium-calcium-silicate ceramic granules were tested in furcation defects and showed promise for bone regeneration (221). Fibrin matrices combined with $\varepsilon$ aminocaproic acid-loaded chitosan nanoparticles were tested in intrabony defects and lead to greater bone regeneration and improved cementum and PDL formation vs. fibrin matrices alone or EMD (222). An in vitro study suggested that fibrin binding promotes Wnt signaling by cementoblasts, providing a possible mechanism for these positive in vivo results (223). Studies in periodontitis models also show that targeting Wnt pathway inhibitors sclerostin $(224,225)$ or GSK3 $\beta$ (226) can improve periodontal bone reformation.

\section{Autologous Platelet Concentrates}

An alternative to recombinant growth factors and bioactive compounds is autologous platelet concentrates (APCs) such as platelet rich plasma (PRP) and platelet rich fibrin (PRF). Platelets release growth factors during early wound healing, and APCs contain factors such as PDGF, TGF- $\beta$, FGF, and IGF $(227,228)$. Various forms of APCs contain differing amounts of platelets as well as fibrin and leukocytes. Differences in preparation and subsequent APC composition affects growth factor concentrations and release profiles, further complicating efforts to compare studies or fully understand APC effects (229, 230). Despite numerous clinical trials and widespread use (231), histologic demonstration of the effect APC on periodontal wound healing is scarce, with the few available animal studies showing variable results. One study of PRP showed improved cementum and bone formation in fenestration defects (232). A platelet pellet was tested with or without GTR barriers, with the platelet pellet promoting increased new cementum formation regardless of barrier inclusion but having no impact on bone formation (233). PRF was tested in a fenestration defect with and without implanted PDL cells (234). PRF or PDL cells alone showed no improvements in bone and cementum formation over empty defects, while combined treatment led to significantly increased bone and cementum. PRF was also tested in periodontal defects and led to reduced inflammation and increased pocket closure but failed to promote bone formation (235).

\section{CELL DELIVERY AND RECRUITMENT PDL Cell Transplantation}

Transplantation of cells into periodontal defects is a widely studied approach for promoting tissue regeneration. Cells derived from patient or donor tissues can be isolated and transplanted into defects to alter wound healing through direct mechanisms, differentiating and forming new tissues. Alternatively, transplanted cells can play indirect roles in tissue regeneration by secreting various signaling factors (236). In particular, mesenchymal stromal cells (MSCs) from oral (e.g., alveolar bone, gingiva, dental pulp, dental papilla, dental follicle, PDL) or extra-oral sources (adipose tissue, bone marrow, etc.) have been extensively investigated for their regenerative potential in animal periodontal defects $(237,238)$. A number of investigations have shown improved results for PDL-derived cells vs. bone or gingiva-derived cells, especially in regards to cementum and PDL formation (239-241). These outcomes, coupled with the critical role of endogenous PDL cells in periodontal wound healing and regeneration, offer further motivation for their use as a therapeutic material.

Cells harvested and cultured from the PDL have been referred to by a variety of names, including PDL fibroblasts, PDL stem cells, or PDL progenitor cells (242-244). Cultured PDL cells, referred to here as PDLCs, fulfill the minimum criteria previously established for MSCs (245, 246), and can meet some of the rigorous criteria proposed for tissue-specific stem cells (247): certain clonal PDLC strains are able to form cementum and PDL-like tissue upon ectopic transplantation into immunocompromised mice (64) and show the ability for self-renewal $(248,249)$.

Significant changes occur between isolation of cells from the PDL and expansion of PDLCs on tissue culture plastic. Even with prospective sorting for specific cell-surface markers, cultured PDLCs expand in a heterogeneous fashion $(67,250)$. Cultured PDLCs also differ significantly from freshly isolated PDL cells in their response to growth factors and other regenerative cues (251). Despite these issues, delivery of cultured PDLCs to experimental periodontal defects tends to result in increased cementum and PDL formation compared to cell-free controls $(252,253)$. Autologous PDLCs have also been tested in clinical trials, with results showing no adverse outcomes, but also no significant benefits over cell-free controls $(254,255)$.

The biomaterial or scaffold used to transplant PDLCs should ensure cell survival, as well as maintain or promote tissue forming potential and/or secretory activity. A wide variety of biomaterials have been used to deliver PDLCs, and this combined therapy generally improves periodontal wound healing (256). Scaffoldfree delivery of PDLCs can also be accomplished using cell sheets. PDL-derived cell sheets have shown potential for periodontal regeneration in animal models (257) and have been utilized in human clinic trials $(254,258)$. Optimal performance of cell sheets requires close adaptation of the sheet to the root surface (240), a role which various carrier or transfer materials can perform. 
A

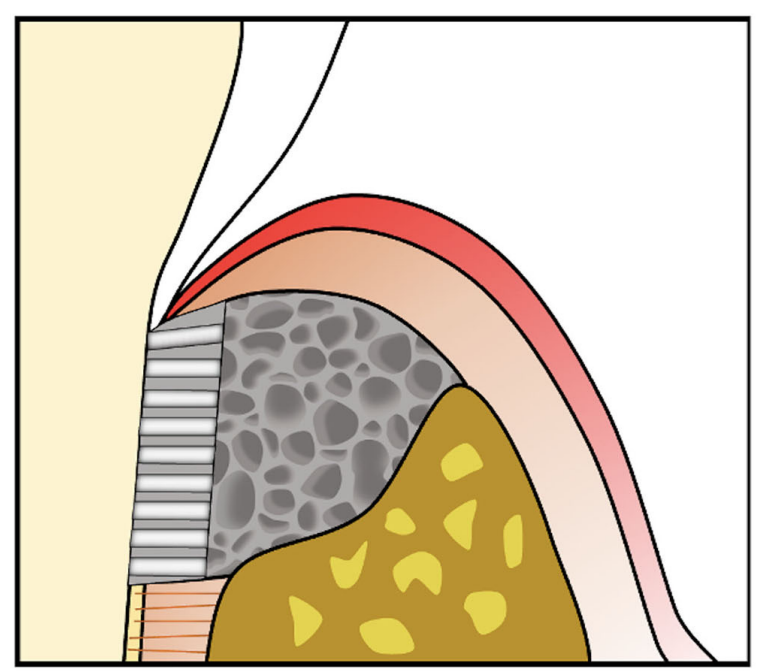

B

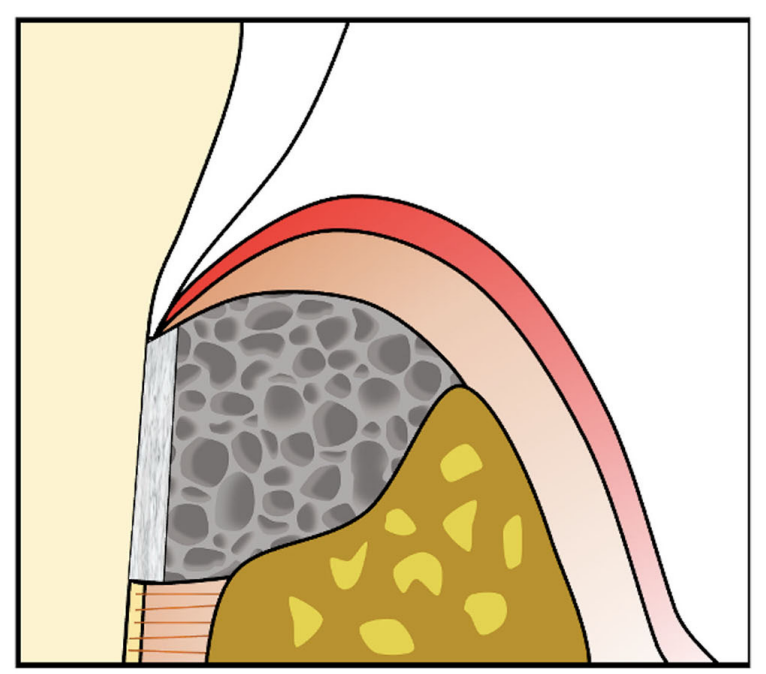

FIGURE 5 | (A) Engineered scaffolds that fill the periodontal defect space can include an aligned region in the PDL space to provide directional guidance for cells together with another material, often containing randomly oriented pores, to fill the space to be replaced by bone. (B) Scaffolds can also support amorphous materials such as cell sheets against the tooth root surface.

Additional scaffolding is also required for space maintenance and promoting bone formation, requiring a combination of cell sheets with membranes, grafting materials and/or tissue engineered scaffolds (see below).

The exact role transplanted PDLCs or other cells play in periodontal tissue regeneration remains unclear. Studies utilizing autologous bone marrow derived stromal cells have shown evidence of transplanted cell differentiation and integration into new periodontal tissues (259-261). Evidence for a direct role by transplanted PDLCs is less consistent, possibly due to variations in the genetic relationship between donor and recipient PDLCs and the immune status of various animal models across studies. For instance, allogeneic PDLCs localized adjacent to, but not within regenerating periodontal bone in immunosuppressed rats $(262,263)$. In another study, few xenogeneic (human) PDLCs were found around regenerating periodontal tissues in immunosuppressed rodents (264). In contrast, allogeneic PDLCs were present as osteoblasts and cementoblasts in immunocompetent rats (265). Variations in scaffold material and design may also have influenced the activity of PDLCs in each of these models. Host immune cells can target both syngeneic and allogeneic transplanted cells for clearance $(266,267)$, and biomaterials can be designed to provide an immunoprotective environment to prolong the survival of transplanted cells $(268,269)$. Alternatively, inclusion of transplanted cells within scaffolds can favorably alter the immune response to implanted biomaterials, reducing the foreign body reaction $(270,271)$.

Recent studies indicate that transplanted PDLCs also play an indirect role in periodontal wound healing through secretion of various factors with immunogenic, angiogenic, or regenerative properties (272-274). PDLC-conditioned media has been delivered to periodontal defects in collagen sponges (273) and collagen barriers (275) and shown to promote new bone formation. PDLCs secrete a variety of extracellular vesicles, including a subgroup of small extracellular vesicles termed exosomes, that carry biologic molecules with paracrine effects (276). Exosomes derived from bone marrow $(277,278)$ or adipose tissue-derived MSCs (279), or exfoliated tooth dental pulp (SHED) (280) and adult dental pulp (281) cells have been tested in periodontal defects. To date, no study has tested PDLCderived exosomes for periodontal regeneration.

Altogether, current evidence suggests that transplanted PDLCs have potential to improve periodontal wound healing but will not play the same role as endogenous PDL-derived cells. Significant translational hurdles face PDLC transplantation, such as sourcing PDLs, identifying and maintaining the multipotent subpopulations, and developing scaffolds for controlled delivery, as well as regulatory and manufacturing challenges such as developing xenogeneic-free culture methods and scaling and maintaining batch consistency. While PDLC-secreted factors can be collected and delivered to promote periodontal wound healing, their benefit over recombinant growth factors or small molecule drugs should be established to justify the potential variability and additional cost inherent in such an approach.

\section{Cell Recruitment}

Recruitment of endogenous cells to periodontal defects may help overcome the limitations of cell activation from residual periodontal tissues or cell transplantation. Stromal derived factor-1, also known as CXCL12, acts as a chemokine at wound sites to recruit cells from local tissues and circulation (282). A portion of PDL cells express the receptor for SDF-1, CXCR4 $(283,284)$. In addition, bone marrow stromal cells transplanted into long bones have been shown to enter periodontal wounds via the circulatory system and participate in tissue regeneration 
A

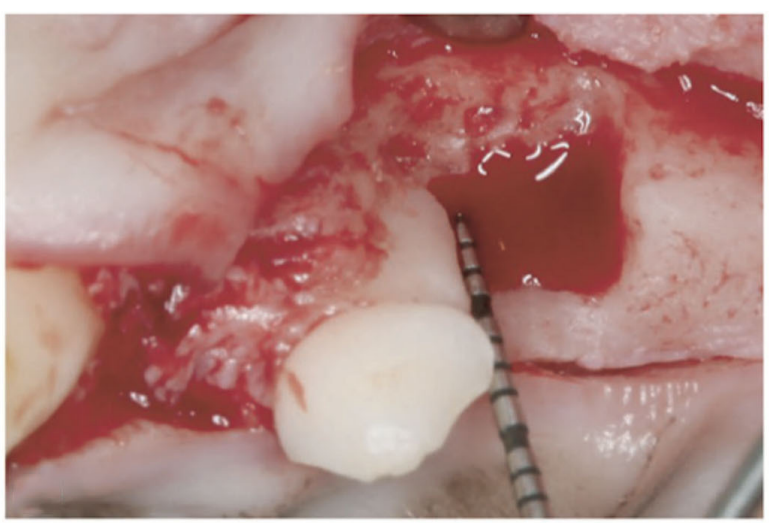

C

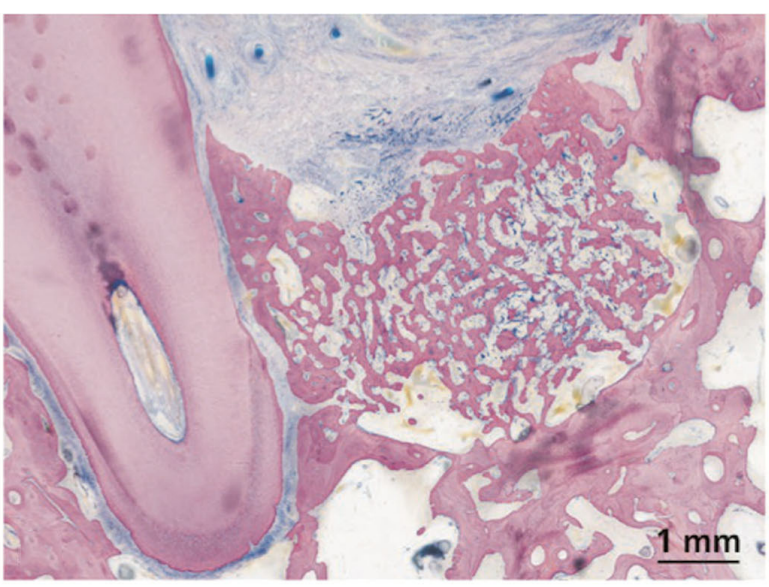

B

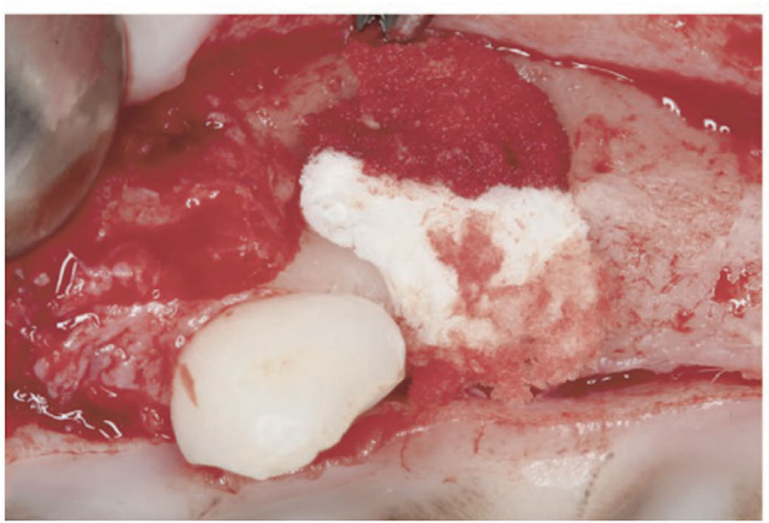

D

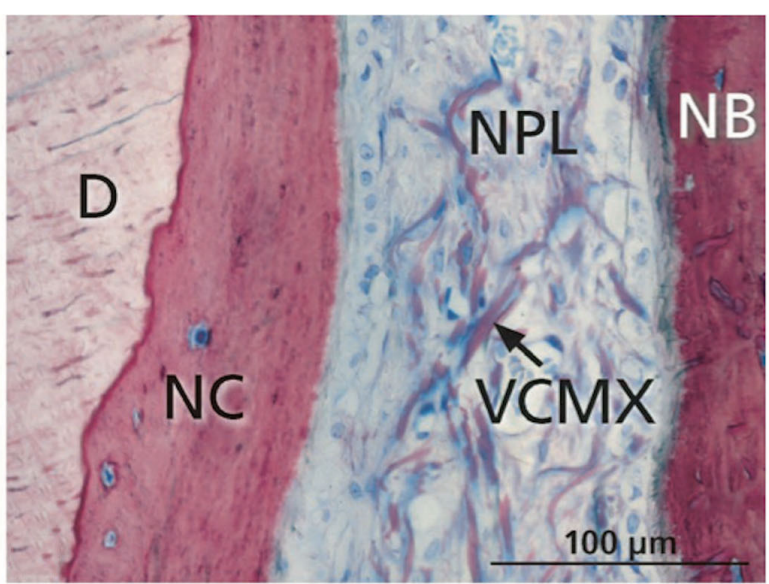

FIGURE 6 | (A) Intrabony defects were created at canine maxillary premolars. (B) Insertion of the volume stable collagen matrix (VCMX). (C) Histologic section from tissues harvested after 12 weeks of healing showing new bone filling the periodontal defect. (D) Histologic section demonstrating new cementum (NC) on the dentin (D) surface, new alveolar bone (NB), and residual scaffold (VCMX) visible in the newly formed PDL (NPL). Reproduced with permission from (309).

$(285,286)$, a process which may be driven by increased SDF-1 expression in injured periodontal tissues (287).

SDF-1 loaded collagen sponges placed within periodontal defects resulted in an increased number of both mesenchymal stromal cells and hematopoietic cells at early time points while immune cells numbers were reduced (288). SDF-1 application also led to an early increase in osteoclast activity at the wound margins followed by increased bone formation later in healing. Gelatin sponges loaded with SDF-1 were tested in intrabony defects and showed improvements in bone, cementum, and PDL formation and fewer infiltrating macrophages (289). Combined delivery of SDF-1 and parathyroid hormone (PTH) loaded collagen barriers has also been investigated, as PTH can promote tissue regeneration and also inhibit inactivation of SDF-1 (290). Combined SDF-1 and PTH delivery increased the number of CXCR4+ and mesenchymal cells and was more effective in promoting bone, PDL, and cementum formation compared to either factor alone. A self-assembling peptide-based hydrogel was used to load SDF-1 and BMP-2, leading to greater bone formation compared to either factor alone, although neither cementum and PDL regeneration or in vivo cell recruitment outcomes were described (291). SDF-1 was paired with IL-4 in stiff gelatin hydrogels to recruit stromal cells while minimizing pro-inflammatory macrophage polarization, with dual factor delivery improving bone fill but not cementum or PDL formation compared to single factors or unloaded hydrogels (292). Despite the promise of SDF-1 mediated cell recruitment in periodontal tissues, studies to date have not clarified if mesenchymal cell recruitment is from distant tissues via circulation or local periodontal tissues.

\section{TISSUE ENGINEERING: REPLICATING THE PERIODONTAL TISSUES}

The field of regenerative medicine was formally introduced to the concept of tissue engineering in the early 1990's $(293,294)$, which is broadly defined as combining scaffolds with cells and/or biologic factors to create and replace functional tissues (295). While significant scientific progress has been made since then, translation of tissue engineered constructs and organs to human clinical trials is rare (296). Periodontal tissue engineering was 
recognized early in the field's development as an opportunity to improve regenerative outcomes around teeth (297-299). Similar to the field in general, few tissue engineered periodontal products have reached clinical translation after more than 30 years of cumulative research.

Periodontal tissue engineering can be seen as a topdown approach, recreating essential anatomic structures of cementum, PDL, and bone ex vivo through compartmentalized, interconnected scaffolds laden with cells and/or growth factors (300). This approach contrasts with GTR and its biologic rationale in some respects. Replicating structural aspects of mature tissues and providing exogenous cells and signaling factors may place less burden on endogenous cells to regenerate periodontal tissues. Scaffolds with similar mechanical properties as mature tissues and with slow or minimal degradation may also be left in place to provide long-term support for extended bone remodeling and full tissue maturation (301). Studies in load-bearing bones indicate a beneficial role for stiff and slow degrading scaffolds which maintain functional support for at least 3 months as mechanical support is transferred from scaffold to maturing bone $(302,303)$. However, little evidence has been provided to support this rationale for periodontal tissue engineering. A notable human case study implanted a tissue engineered PCL-HAp scaffold into a human periodontal defect (304). Minimal scaffold degradation occurred during the initial 1 year period, after which the scaffold became exposed to the oral cavity, necessitating its removal.

Taking cues from the organized fibrous structure of the mature PDL, engineered scaffolds can guide cell alignment and new tissue formation along polymeric struts that abut the root surface [see reviews $(305,306)$ ] (Figure 5A). The rationale behind these approaches is that directing cell migration and orientation will increase the likelihood of formation of organized PDL fibers inserting into new cementum. In vivo studies have shown these scaffolds promote formation of aligned PDL structures (307) and could support increased new cementum or bone, especially when viral vectors for growth factor expression were used to transduce transplanted or host cells $(171,308)$.

In contrast, engineered periodontal scaffolds can localize amorphous materials such as cell sheets in the PDL space, using porous scaffolding to support the material adjacent to the root surface and fill the periodontal defect (Figure 5B). Cell sheet-scaffold constructs have been tested in small (240) and large animal models (239), showing promise for supporting formation of new cementum with inserting PDL fibers in the absence of structural guidance. A recent study tested a porous, crosslinked collagen scaffold, previously developed for gingival tissue augmentation, in canine periodontal defects without additional materials, cells or signaling factors (309). This "volume stable" scaffold provided sufficient space maintenance and wound stability to allow infiltration of host cells and formation of new bone, cementum, and PDL (Figure 6), illustrating the potential for scaffold designs that support endogenous periodontal regenerative activity.
Hurdles facing other engineered tissues are relevant in periodontal defects and clinical translation of tissue engineered periodontal scaffolds is further complicated by several factors. Periodontal scaffolds must balance mechanical properties for space maintenance with the proper degradation behavior. Stiff scaffolds that adapt to and fill periodontal defects may need to be individualized, which currently requires surface and radiographic imaging of defects, followed by computer-aided manufacturing (e.g., 3D printing), and then delivery. Existing soft tissues must be able to cover the scaffold and protect it from colonization of oral bacteria, which is challenging at sites with large bone defects and gingival recession. Finally, as the complexity of a tissue engineered scaffold increases, so will also the cost and time required for fabrication, which may limit widespread adoption and clinical use.

\section{CONCLUSIONS}

Strategies for developing new periodontal therapies should incorporate principles gleaned from guided tissue regeneration, with wound stability, space maintenance, and soft tissue coverage remaining primary considerations. Approaches which support or promote infiltration of cells from residual PDL at the defect periphery may be more likely to lead to formation of new cementum and PDL. Other approaches, such as replicating mature periodontal structures with biomaterials, application of multiple growth factors, delivering cells, or recruiting host cells have promise, but continue to show variable results and do not necessarily replicate key events of endogenous periodontal wound healing.

Future studies should consider that new periodontal bone formation is not necessarily accompanied by new cementum and PDL. Reporting quantitative outcomes for cementum and PDL and formation continues to be inconsistent and will be challenging to standardize across different animal models. Pre-clinical studies in large animals should also report on gingival tissue outcomes, such as formation of junctional epithelium and connective tissue attachment, as these outcomes are closely related to formation of new cementum and PDL.

Finally, new strategies should be carefully designed in consideration that increasing complexity may mean clinical translation is even less likely. For instance, scaffolds seeded with autologous PDL cells may be unlikely to reach regular clinical use due to the need for extracted teeth to source cells and the time and cost required for cell processing and preparation. In contrast, application of autologous platelet concentrates such PRF has been widely adopted due to its low cost and ease of use despite limited pre-clinical evidence to confirm its ability to promote periodontal tissue regeneration. Regardless of the challenges facing the field, long-term clinical studies have demonstrated that periodontal tissue regeneration can be achieved when utilizing techniques informed by strong biologic rationale. 


\section{AUTHOR CONTRIBUTIONS}

DF and DB: conception, design, and obtaining of funding. DF: writing of manuscript. DF, JC, and DB: review and final approval of the manuscript. All authors contributed to the article and approved the submitted version.

\section{REFERENCES}

1. Nanci A, Bosshardt DD. Structure of periodontal tissues in health and disease. Periodontology. (2006) 40:11-28. doi: 10.1111/j.1600-0757.2005.00141.x

2. Kinane DF, Stathopoulou PG, Papapanou PN. Periodontal diseases. Nat Rev Dis Primers. (2017) 3:17038. doi: 10.1038/nrdp.2017.38

3. Caton JG, Zander HA. The attachment between tooth and gingival tissues after periodic root planing and soft tissue curettage. J Periodontol. (1979) 50:462-6. doi: 10.1902/jop.1979.50.9.462

4. Sculean A, Gruber R, Bosshardt DD. Soft tissue wound healing around teeth and dental implants. J Clin Periodontol. (2014) 41:S6-S22. doi: $10.1111 /$ jcpe. 12206

5. Cortellini P, Buti J, Pini Prato G, Tonetti MS. Periodontal regeneration compared with access flap surgery in human intra-bony defects 20-year follow-up of a randomized clinical trial: tooth retention, periodontitis recurrence and costs. J Clin Periodontol. (2017) 44:58-66. doi: $10.1111 /$ jcpe. 12638

6. Noguchi S, Ukai T, Kuramoto A, Yoshinaga Y, Nakamura H, Takamori Y, et al. The histopathological comparison on the destruction of the periodontal tissue between normal junctional epithelium and long junctional epithelium. J Periodontal Res. (2017) 52:74-82. doi: 10.1111/jre.12370

7. Carnevale G, Kaldahl WB. Osseous resective surgery. Periodontology. (2000) 22:59-87. doi: 10.1034/j.1600-0757.2000.2220106.x

8. Caton J, Nyman S. Histometric evaluation of periodontal surgery: III. The effect of bone resection on the connective tissue attachment level. $J$ Periodontol. (1981) 52:405-9. doi: 10.1902/jop.1981.52.8.405

9. Wang H. Position paper: periodontal regeneration. J Periodontol. (2005) 76:1601-22. doi: 10.1902/jop.2005.76.9.1601

10. MacNeil RL, Somerman MJ. Development and regeneration of the periodontium: parallels and contrasts. Periodontology. (1999) 19:8-20. doi: 10.1111/j.1600-0757.1999.tb00144.x

11. Bosshardt DD, Stadlinger B, Terheyden H. Cell-to-cell communicationperiodontal regeneration. Clin Oral Implants Res. (2015) 26:229-39. doi: $10.1111 /$ clr. 12543

12. de Jong T, Bakker AD, Everts V, Smit TH. The intricate anatomy of the periodontal ligament and its development: lessons for periodontal regeneration. J Periodontal Res. (2017) 52:965-74. doi: 10.1111/jre.12477

13. Schallhorn RG, Hiatt WH, Boyce W. Iliac transplants in periodontal therapy. J Periodontol. (1970) 41:566-80. doi: 10.1902/jop.1970.41.10.566

14. Dragoo MR, Sullivan HC, A. clinical and histological evaluation of autogenous iliac bone grafts in humans. I Wound healing 2 to 8 months. $J$ Periodontol. (1973) 44:599-613. doi: 10.1902/jop.1973.44.10.599

15. Moskow BS, Karsh F, Stein SD. Histological assessment of autogenous bone graft. A case report and critical evaluation. J Periodontol. (1979) 50:291-300. doi: 10.1902/jop.1979.50.6.291

16. Caton J, Nyman S, Zander H. Histometric evaluation of periodontal surgery. II Connective tissue attachment levels after four regenerative procedures. J Clin Periodontol. (1980) 7:224-31. doi: 10.1111/j.1600-051X.1980.tb01 965.x

17. Pitaru S, McCulloch CAG, Narayanan SA. Cellular origins and differentiation control mechanisms during periodontal development and wound healing. J Periodontal Res. (1994) 29:81-94. doi: 10.1111/j.1600-0765.1994.tb01095.x

18. Melcher AH. On the repair potential of periodontal tissues. J Periodontol. (1976) 47:256-60. doi: 10.1902/jop.1976.47.5.256
FUNDING

Funding for this work was provided by the University of Rochester, Joan Wright Goodman Dissertation Fellowship and CSTI Pilot Program (UL1 TR002001) to DF, and from the National Institutes of Health to DB (R01AR064200 and P30AR069655).

19. Karring T, Nyman S, Lindhe J. Healing following implantation of periodontitis affected roots into bone tissue. J Clin Periodontol. (1980) 7:96-105. doi: 10.1111/j.1600-051X.1980.tb01952.x

20. Nyman S, Karring T, Lindhe J, Plantén S. Healing following implantation of periodontitis-affected roots into gingival connective tissue. J Clin Periodontol. (1980) 7:394-401. doi: 10.1111/j.1600-051X.1980.tb02012.x

21. Karring T, Isidor F, Nyman S, Lindhe J. New attachment formation on teeth with a reduced but healthy periodontal ligament. J Clin Periodontol. (1985) 12:51-60. doi: 10.1111/j.1600-051X.1985.tb01353.x

22. Nyman S, Gottlow J, Karring T, Lindhe J. The regenerative potential of the periodontal ligament. J Clin Periodontol. (1982) 9:257-65. doi: 10.1111/j.1600-051X.1982.tb02065.x

23. Gottlow J, Nyman S, Karring T, Lindhe J. New attachment formation as the result of controlled tissue regeneration. J Clin Periodontol. (1984) 11:494503. doi: 10.1111/j.1600-051X.1984.tb00901.x

24. Caton J, Wagener C, Polson A, Nyman S, Frantz B, Bouwsma O, et al. Guided tissue regeneration in interproximal defects in the monkey. Int J Periodont Restorat Dentist. (1992) 12:266-77.

25. Gottlow J, Nyman S, Lindhe J, Karring T, Wennström J. New attachment formation in the human periodontium by guided tissue regeneration. Case reports. J Clin Periodontol. (1986) 13:604-16. doi: 10.1111/j.1600-051X.1986.tb00854.x

26. Nyman S, Gottlow J, Lindhe J, Karring T, Wennstrom J. New attachment formation by guided tissue regeneration. J Periodontal Res. (1987) 22:252-4. doi: 10.1111/j.1600-0765.1987.tb01581.x

27. Nyman S, Lindhe J, Karring T, Rylander H. New attachment following surgical treatment of human periodontal disease. J Clin Periodontol. (1982) 9:290-6. doi: 10.1111/j.1600-051X.1982.tb02095.x

28. Caffesse RG, Nasjleti CE, Anderson GB, Lopatin DE, Smith BA, Morrison EC. Periodontal healing following guided tissue regeneration with citric acid and fibronectin application. J Periodontol. (1991) 62:21-9. doi: 10.1902/jop.1991.62.1.21

29. Caton JG, Greenstein G. Factors related to periodontal regeneration. Periodontology. (1993) 1:9-15. doi: 10.1111/j.1600-0757.1993.tb00202.x

30. Polson AM, Frederick GT, Ladenheim S, Hanes PJ. The production of a root surface smear layer by instrumentation and its removal by citric acid. J Periodontol. (1984) 55:443-6. doi: 10.1902/jop.1984.55.8.443

31. Lowenguth RA, Blieden TM. Periodontal regeneration: root surface demineralization. Periodontology. (1993) 1:54-68. doi: 10.1111/j.1600-0757.1993.tb00207.x

32. Polson AM, Proye MP. Fibrin linkage: a precursor for new attachment. $J$ Periodontol. (1983) 54:141-7. doi: 10.1902/jop.1983.54.3.141

33. Mariotti A. Efficacy of chemical root surface modifiers in the treatment of periodontal disease. A systematic review. Ann Periodontol. (2003) 8:205-26. doi: 10.1902/annals.2003.8.1.205

34. Wikesjö UM, Selvig KA. Periodontal wound healing and regeneration. Periodontology. (1999) 19:21-39. doi: 10.1111/j.1600-0757.1999.tb00145.x

35. Dreyer WP, VAN Heerden JD. The effect of citric acid on the healing of periodontal ligament-free, healthy roots, horizontally implanted against bone and gingival connective tissue. J Periodontal Res. (1986) 21:210-20. doi: 10.1111/j.1600-0765.1986.tb01453.x

36. Aukhil I, Pettersson E, Suggs C. Periodontal wound healing in the absence of periodontal ligament cells. J Periodontol. (1987) 58:71-7. doi: 10.1902/jop.1987.58.2.71

37. Wikesjö UME, Claffey N, Christersson LA, Franzetti LC, Genco RJ, Terranova VP, et al. Repair of periodontal furcation defects in beagle dogs 
following reconstructive surgery including root surface demineralization with tetracycline hydrochloride and topical fibronectin application. J Clin Periodontol. (1988) 15:73-80. doi: 10.1111/j.1600-051X.1988.tb01558.x

38. Nyman S, Houston F, Sarhed G, Lindhe J, Karring T. Healing following reimplantation of teeth subjected to root planing and citric acid treatment. J Clin Periodontol. (1985) 12:294-305. doi: 10.1111/j.1600-051X.1985.tb02295.x

39. Wikesjö UME, Kean CJC, Zimmerman GJ. Periodontal repair in dogs: supraalveolar defect models for evaluation of safety and efficacy of periodontal reconstructive therapy. J Periodontol. (1994) 65:1151-7. doi: 10.1902/jop.1994.65.12.1151

40. Haney JM, Nilvéus RE, McMillan PJ, Wikesjö UM. Periodontal repair in dogs: expanded polytetrafluoroethylene barrier membranes support wound stabilization and enhance bone regeneration. J Periodontol. (1993) 64:883. doi: 10.1902/jop.1993.64.9.883

41. Sigurdsson TJ, Hardwick R, Bogle GC, Wikesjö UM. Periodontal repair in dogs: space provision by reinforced ePTFE membranes enhances bone and cementum regeneration in large supraalveolar defects. J Periodontol. (1994) 65:350-6. doi: 10.1902/jop.1994.65.4.350

42. Wikesjö UM, Lim WH, Thomson RC, Hardwick WR. Periodontal repair in dogs: gingival tissue occlusion, a critical requirement for GTR? J Clin Periodontol. (2003) 30:655-64. doi: 10.1034/j.1600-051X.2003.00362.x

43. Polimeni G, Susin C, Wikesjö UME. Regenerative potential and healing dynamics of the periodontium: a critical-size supra-alveolar periodontal defect study. J Clin Periodontol. (2009) 36:258-64. doi: 10.1111/j.1600-051X.2008.01369.x

44. Hiatt WH, Schallhorn RG. Intraoral transplants of cancellous bone and marrow in periodontal lesions. J Periodontol. (1973) 44:194-208. doi: 10.1902/jop.1973.44.4.194

45. Polimeni G, Albandar JM, Wikesjö UME. Prognostic factors for alveolar regeneration: effect of space provision. J Clin Periodontol. (2005) 32:951-4. doi: 10.1111/j.1600-051X.2005.00763.x

46. Tonetti MS, Prato GP, Cortellini P. Factors affecting the healing response of intrabony defects following guided tissue regeneration and access flap surgery. $J$ Clin Periodontol. (1996) 23:548-56. doi: 10.1111/j.1600-051X.1996.tb01823.x

47. Trombelli L, Lee MB, Promsudthi A, Guglielmoni PG, Wikesjö UM. Periodontal repair in dogs: histologic observations of guided tissue regeneration with a prostaglandin E1 analog/methacrylate composite. J Clin Periodontol. (1999) 26:381-7. doi: 10.1034/j.1600-051X.1999.260608.x

48. Dickinson DP, Coleman BG, Batrice N, Lee J, Koli K, Pennington C, et al. Events of wound healing/regeneration in the canine supraalveolar periodontal defect model. J Clin Periodontol. (2013) 40:527-41. doi: 10.1111 jicpe. 12055

49. Iglhaut J, Aukhil I, Simpson DM, Johnston MC, Koch G. Progenitor cell kinetics during guided tissue regeneration in experimental periodontal wounds. J Periodontal Res. (1988) 23:107-17. doi: 10.1111/j.1600-0765.1988.tb01342.x

50. Aukhil I, Iglhaut J. Periodontal ligament cell kinetics following experimental regenerative procedures. J Clin Periodontol. (1988) 15:374-82. doi: 10.1111/j.1600-051X.1988.tb01015.x

51. Herr Y, Matsuura M, Lin WL, Genco RJ, Cho MI. The origin of fibroblasts and their role in the early stages of horizontal furcation defect healing in the beagle dog. J Periodontol. (1995) 66:716-30. doi: 10.1902/jop.1995.66.8.716

52. Christgau M, Caffesse RG, Schmalz G, D'Souza RN. Extracellular matrix expression and periodontal wound-healing dynamics following guided tissue regeneration therapy in canine furcation defects. J Clin Periodontol. (2007) 34:691-708. doi: 10.1111/j.1600-051X.2007.01097.x

53. Matsuura M, Herr Y, Han KY, Lin WL, Genco RJ, Cho MI. Immunohistochemical expression of extracellular matrix components of normal and healing periodontal tissues in the beagle dog. J Periodontol. (1995) 66:579-93. doi: 10.1902/jop.1995.66.7.579

54. Graziani F, Laurell L, Tonetti M, Gottlow J, Berglundh T. Periodontal wound healing following GTR therapy of dehiscence-type defects in the monkey: short-, medium- and long-term healing. J Clin Periodontol. (2005) 32:905-14. doi: 10.1111/j.1600-051X.2005.00789.x
55. Caton JG, DeFuria EL, Polson AM, Nyman S. Periodontal regeneration via selective cell repopulation. J Periodontol. (1987) 58:546-52. doi: 10.1902/jop.1987.58.8.546

56. Sander L, Karring T. Healing of periodontal lesions in monkeys following the guided tissue regeneration procedure. A histological study. J Clin Periodontol. (1995) 22:332-7. doi: 10.1111/j.1600-051X.1995.tb00156.x

57. Polimeni G, Xiropaidis AV, Wikesjö UME. Biology and principles of periodontal wound healing/regeneration. Periodontology. (2006) 41:30-47. doi: $10.1111 / j .1600-0757.2006 .00157 . x$

58. McCulloch CA. Historical perspective of periodontal progenitor cells: early studies that clarified identity and function. Curr Oral Health Rep. (2015) 2:227-35. doi: 10.1007/s40496-015-0061-z

59. Gould TRL, Melcher AH, Brunette DM. Migration and division of progenitor cell populations in periodontal ligament after wounding. $J$ Periodontal Res. (1980) 15:20-42. doi: 10.1111/j.1600-0765.1980.tb00258.x

60. McCulloch CAG, Melcher AH. Cell migration in the periodontal ligament of mice. J Periodontal Res. (1983) 18:339-52. doi: 10.1111/j.1600-0765.1983.tb00369.x

61. McCulloch CA. Progenitor cell populations in the periodontal ligament of mice. Anat Rec. (1985) 211:258-62. doi: 10.1002/ar.1092110305

62. McCulloch CAG, Nemeth E, Lowenberg B, Melcher AH. Paravascular cells in endosteal spaces of alveolar bone contribute to periodontal ligament cell populations. Anat Rec. (1987) 219:233-42. doi: 10.1002/ar.1092190304

63. Chen SC, Marino V, Gronthos S, Bartold PM. Location of putative stem cells in human periodontal ligament. J Periodontal Res. (2006) 41:547-53. doi: 10.1111/j.1600-0765.2006.00904.x

64. Seo BM, Miura M, Gronthos S, Bartold PM, Batouli S, Brahim J, et al. Investigation of multipotent postnatal stem cells from human periodontal ligament. Lancet. (2004) 364:149-55. doi: 10.1016/S0140-6736(04)16627-0

65. Roguljic H, Matthews BG, Yang W, Cvija H, Mina M, Kalajzic I. In vivo identification of periodontal progenitor cells. J Dent Res. (2013) 92:709-15. doi: 10.1177/0022034513493434

66. Roeder E, Matthews BG, Kalajzic I. Visual reporters for study of the osteoblast lineage. Bone. (2016) 92:189-95. doi: 10.1016/j.bone.2016.09.004

67. Men Y, Wang Y, Yi Y, Jing D, Luo W, Shen B, et al. Gli1+ periodontium stem cells are regulated by osteocytes and occlusal force. Dev Cell. (2020) 54:639-54.e6. doi: 10.1016/j.devcel.2020.06.006

68. Perera KA, Tonge $\mathrm{CH}$. Fibroblast cell proliferation in the mouse molar periodontal ligament. J Anat. (1981) 133(Pt 1):77-90.

69. Xie $\mathrm{X}, \mathrm{Xu} \mathrm{C}$, Zhao $\mathrm{H}$, Wang J, Feng JQ. A biphasic feature of Gli1(+)-mesenchymal progenitors during cementogenesis that is positively controlled by Wnt/ $\beta$-catenin signaling. J Dent Res. 2021:220345211007429. doi: 10.1177/00220345211007429

70. Yuan X, Pei X, Zhao Y, Tulu US, Liu B, Helms JA, et al. Wnt-responsive PDL population effectuates extraction socket healing. J Dent Res. (2018) 97:803-9. doi: $10.1177 / 0022034518755719$

71. Arioka M, Dawid IM, Cuevas PL, Coyac BR, Leahy B, Wang L, et al. Accelerating socket repair via WNT3A curtails alveolar ridge resorption. J Dent Res. 2021:00220345211019922. doi: 10.1177/00220345211019922

72. Hosoya A, Ninomiya T, Hiraga T, Zhao C, Yoshiba K, Yoshiba N, et al. Alveolar bone regeneration of subcutaneously transplanted rat molar. Bone. (2008) 42:350-7. doi: 10.1016/j.bone.2007.09.054

73. Hosoya A, Ninomiya T, Hiraga T, Yoshiba K, Yoshiba N, Kasahara E, et al. Potential of periodontal ligament cells to regenerate alveolar bone. J Oral Biosci. (2010) 52:72-80. doi: 10.1016/S1349-0079(10)80035-0

74. Hosoya A, Shalehin N, Takebe H, Fujii S, Seki Y, Mizoguchi T, et al. Stem cell properties of Gli1-positive cells in the periodontal ligament. J Oral Biosci. (2020) 62:299-305. doi: 10.1016/j.job.2020.08.002

75. Zhao J, Faure L, Adameyko I, Sharpe PT. Stem cell contributions to cementoblast differentiation in healthy periodontal ligament and periodontitis. Stem Cells. (2021) 39:92-102. doi: 10.1002/stem.3288

76. Stavropoulos A, Bertl K, Spineli LM, Sculean A, Cortellini P, Tonetti M. Medium- and long-term clinical benefits of periodontal regenerative/reconstructive procedures in intrabony defects: systematic review and network meta-analysis of randomized controlled clinical studies. J Clin Periodontol. (2021) 48:410-30. doi: 10.1111/jcpe.13409 
77. Cortellini P, Tonetti MS. Focus on intrabony defects: guided tissue regeneration. Periodontology. (2000) 22:104-32. doi: 10.1034/j.1600-0757.2000.2220108.x

78. Zhao S, Pinholt EM, Madsen JE, Donath K. Histological evaluation of different biodegradable and non-biodegradable membranes implanted subcutaneously in rats. J Craniomaxillofac Surg. (2000) 28:116-22. doi: $10.1054 / \mathrm{jcms} .2000 .0127$

79. Korzinskas T, Jung O, Smeets R, Stojanovic S, Najman S, Glenske K, et al. In vivo analysis of the biocompatibility and macrophage response of a nonresorbable PTFE membrane for guided bone regeneration. Int J Mol Sci. (2018) 19:2952. doi: 10.3390/ijms19102952

80. Carbonell JM, Martín IS, Santos A, Pujol A, Sanz-Moliner JD, Nart J. High-density polytetrafluoroethylene membranes in guided bone and tissue regeneration procedures: a literature review. Int J Oral Maxillofac Surg. (2014) 43:75-84. doi: 10.1016/j.ijom.2013.05.017

81. Marouf HA, El-Guindi HM. Efficacy of high-density versus semipermeable PTFE membranes in an elderly experimental model. Oral Surg Oral Med Oral Pathol Oral Radiol Endodontol. (2000) 89:164-70. doi: $10.1067 /$ moe.2000.98922

82. Tonetti MS, Pini-Prato G, Cortellini P. Periodontal regeneration of human intrabony defects. IV Determinants of healing response. J Periodontol. (1993) 64:934-40. doi: 10.1902/jop.1993.64.10.934

83. Murphy KG, Gunsolley JC. Guided tissue regeneration for the treatment of periodontal intrabony and furcation defects. A systematic review. Ann Periodontol. (2003) 8:266-302. doi: 10.1902/annals.2003.8.1.266

84. Benic GI, Hämmerle CHF. Horizontal bone augmentation by means of guided bone regeneration. Periodontology. (2014) 66:13-40. doi: $10.1111 /$ prd.12039

85. Behring J, Junker R, Walboomers XF, Chessnut B, Jansen JA. Toward guided tissue and bone regeneration: morphology, attachment, proliferation, and migration of cells cultured on collagen barrier membranes. A systematic review. Odontology. (2008) 96:1-11. doi: 10.1007/s10266-008-0087-y

86. Delgado LM, Bayon Y, Pandit A, Zeugolis DI. To cross-link or not to cross-link? Cross-linking associated foreign body response of collagen-based devices. Tissue Eng B: Rev. (2014) 21:298-313. doi: 10.1089/ten.teb.2014.0290

87. Rothamel D, Schwarz F, Sager M, Herten M, Sculean A, Becker J. Biodegradation of differently cross-linked collagen membranes: an experimental study in the rat. Clin Oral Implants Res. (2005) 16:369-78. doi: 10.1111/j.1600-0501.2005.01108.x

88. Schwarz F, Rothamel D, Herten M, Wüstefeld M, Sager M, Ferrari D, et al. Immunohistochemical characterization of guided bone regeneration at a dehiscence-type defect using different barrier membranes: an experimental study in dogs. Clin Oral Implants Res. (2008) 19:402-15. doi: 10.1111/j.1600-0501.2007.01486.x

89. Gentile P, Chiono V, Tonda-Turo C, Ferreira AM, Ciardelli G. Polymeric membranes for guided bone regeneration. Biotechnol J. (2011) 6:1187-97. doi: 10.1002/biot.201100294

90. von Arx T, Broggini N, Jensen SS, Bornstein MM, Schenk RK, Buser D. Membrane durability and tissue response of different bioresorbable barrier membranes: a histologic study in the rabbit calvarium. Int J Oral Maxillofac Implants. (2005) 20:843-53.

91. Hürzeler MB, Quiñones CR, Hutmacher D, Schüpbach P. Guided bone regeneration around dental implants in the atrophic alveolar ridge using a bioresorbable barrier. An experimental study in the monkey. Clin Oral Implants Res. (1997) 8:323-31. doi: 10.1034/j.1600-0501.1997.080411.x

92. Sheikh Z, Qureshi J, Alshahrani AM, Nassar H, Ikeda Y, Glogauer M, et al. Collagen based barrier membranes for periodontal guided bone regeneration applications. Odontology. (2017) 105:1-12. doi: 10.1007/s10266-016-0267-0

93. Wang J, Wang L, Zhou Z, Lai H, Xu P, Liao L, et al. Biodegradable polymer membranes applied in guided bone/tissue regeneration: a review. Polymers. (2016) 8:115. doi: 10.3390/polym8040115

94. Susin C, Fiorini T, Lee J, De Stefano JA, Dickinson DP, Wikesjo UM. Wound healing following surgical and regenerative periodontal therapy. Periodontology. (2015) 68:83-98. doi: 10.1111/prd.12057

95. Sculean A, Nikolidakis D, Schwarz F. Regeneration of periodontal tissues: combinations of barrier membranes and grafting materials-biological foundation and preclinical evidence: a systematic review. J Clin Periodontol. (2008) 35:106-16. doi: 10.1111/j.1600-051X.2008.01263.x
96. Bottino MC, Thomas V, Schmidt G, Vohra YK, Chu TM, Kowolik MJ, et al. Recent advances in the development of GTR/GBR membranes for periodontal regeneration-a materials perspective. Dent Mater. (2012) 28:703-21. doi: 10.1016/j.dental.2012.04.022

97. Florjanski W, Orzeszek S, Olchowy A, Grychowska N, Wieckiewicz W, Malysa A, et al. Modifications of polymeric membranes used in guided tissue and bone regeneration. Polymers. (2019) 11:782. doi: $10.3390 /$ polym 11050782

98. Carlo Reis EC, Borges APB, Araújo MVF, Mendes VC, Guan L, Davies JE. Periodontal regeneration using a bilayered PLGA/calcium phosphate construct. Biomaterials. (2011) 32:9244-53. doi: 10.1016/j.biomaterials.2011.08.040

99. Reis EC, Borges AP, del Carlo RJ, Oliveira PM, Sepúlveda RV, Fernandes $\mathrm{NA}$, et al. Guided tissue regeneration using rigid absorbable membranes in the dog model of chronic furcation defect. Acta Odontol Scand. (2013) 71:372-80. doi: 10.3109/00016357.2012.680909

100. Kishan AP, Cosgriff-Hernandez EM. Recent advancements in electrospinning design for tissue engineering applications: a review. $J$ Biomed Mater Res A. (2017) 105:2892-905. doi: 10.1002/jbm.a.36124

101. Cheng H, Yang X, Che X, Yang M, Zhai G. Biomedical application and controlled drug release of electrospun fibrous materials. Mater Sci Eng C. (2018) 90:750-63. doi: 10.1016/j.msec.2018.05.007

102. Zhuang $\mathrm{Y}$, Lin $\mathrm{K}, \mathrm{Yu} \mathrm{H}$. Advance of nano-composite electrospun fibers in periodontal regeneration. Front Chem. (2019) 7:495. doi: $10.3389 /$ fchem. 2019.00495

103. Chen CC, Lee SY, Teng NC, Hu HT, Huang PC, Yang JC. In vitro and in vivo studies of hydrophilic electrospun PLA95/ $\beta$-TCP membranes for guided tissue regeneration (GTR) applications. Nanomaterials. (2019) 9:599. doi: 10.3390/nano9040599

104. Giannobile WV. Periodontal tissue engineering by growth factors. Bone. (1996) 19(1 Suppl):23s-37s. doi: 10.1016/S8756-3282(96)00127-5

105. Okada H, Murakami S. Cytokine expression in periodontal health and disease. Critic Rev Oral Biol Med. (1998) 9:248-66. doi: 10.1177/10454411980090030101

106. Gao J, Symons AL, Bartold PM. Expression of transforming growth factorbeta 1 (TGF- $\beta 1$ ) in the developing periodontium of rats. J Dent Res. (1998) 77:1708-16. doi: 10.1177/00220345980770090701

107. Gao J, Symons AL, Bartold PM. Expression of transforming growth factorbeta receptors types II and III within various cells in the rat periodontium. $J$ Periodontal Res. (1999) 34:113-22. doi: 10.1111/j.1600-0765.1999.tb02230.x

108. Parkar MH, Kuru L, Giouzeli M, Olsen I. Expression of growth-factor receptors in normal and regenerating human periodontal cells. Arch Oral Biol. (2001) 46:275-84. doi: 10.1016/S0003-9969(00)00099-6

109. Green RJ, Usui ML, Hart CE, Ammons WF, Narayanan AS. Immunolocalization of platelet-derived growth factor A and B chains and PDGF- $\alpha$ and $\beta$ receptors in human gingival wounds. J Periodontal Res. (1997) 32:209-14. doi: 10.1111/j.1600-0765.1997.tb00526.x

110. Gao J, Jordan TW, Cutress TW. Immunolocalization growth factor (bFGF) in human periodontal ligament (PDL) tissue. J Periodontal Res. (1996) 31:260-4. doi: 10.1111/j.1600-0765.1996.tb00491.x

111. Sako E, Hosomichi J. Alteration of bFGF expression with growth and age in rat molar periodontal ligament. Angle Orthod. (2010) 80:904-11. doi: 10.2319/011910-38.1

112. Götz W, Heinen $\mathrm{M}$, Lossdörfer S, Jäger A. Immunohistochemical localization of components of the insulin-like growth factor system in human permanent teeth. Arch Oral Biol. (2006) 51:387-95. doi: 10.1016/j.archoralbio.2005.10.005

113. Götz W, Kunert D, Zhang D, Kawarizadeh A, Lossdörfer S, Jäger A. Insulin-like growth factor system components in the periodontium during tooth root resorption and early repair processes in the rat. Eur J Oral Sci. (2006) 114:318-27. doi: 10.1111/j.1600-0722.2006.00 381.x

114. Åberg T, Wozney J, Thesleff I. Expression patterns of bone morphogenetic proteins (Bmps) in the developing mouse tooth suggest roles in morphogenesis and cell differentiation. Dev Dyn. (1997) 210:383-96. doi: 10. 1002/(SICI)1097-0177(199712)210:4<383::AID-AJA3>3.0.CO;2-C

115. Rakian A, Yang WC, Gluhak-Heinrich J, Cui Y, Harris MA, Villarreal D, et al. Bone morphogenetic protein-2 gene controls tooth root development 
in coordination with formation of the periodontium. Int J Oral Sci. (2013) 5:75-84. doi: 10.1038/ijos.2013.41

116. Ivanovski S, Li H, Haase HR, Bartold PM. Expression of bone associated macromolecules by gingival and periodontal ligament fibroblasts. $J$ Periodontal Res. (2001) 36:131-41. doi: 10.1034/j.1600-0765.2001.360301.x

117. Ivanovski S, Li H, Daley T, Bartold PM. An immunohistochemical study of matrix molecules associated with barrier membrane-mediated periodontal wound healing. J Periodontal Res. (2000) 35:115-26. doi: 10.1034/j.1600-0765.2000.035003115.x

118. Amar S, Chung KM, Nam SH, Karatzas S, Myokai F, Van Dyke TE. Markers of bone and cementum formation accumulate in tissues regenerated in periodontal defects treated with expanded polytetrafluoroethylene membranes. J Periodontal Res. (1997) 32:148-58. doi: 10.1111/j.1600-0765.1997.tb01397.x

119. Sigurdsson TJ, Tatakis DN, Lee MB, Wikesjö UM. Periodontal regenerative potential of space-providing expanded polytetrafluoroethylene membranes and recombinant human bone morphogenetic proteins. J Periodontol. (1995) 66:511-21. doi: 10.1902/jop.1995.66.6.511

120. Sigurdsson TJ, Lee MB, Kubota K, Turek TJ, Wozney JM, Wikesjö UME. Periodontal repair in dogs: recombinant human bone morphogenetic protein-2 significantly enhances periodontal regeneration. J Periodontol. (1995) 66:131-8. doi: 10.1902/jop.1995.66.2.131

121. King GN, King N, Cruchley AT, Wozney JM, Hughes FJ. Recombinant human bone morphogenetic protein-2 promotes wound healing in rat periodontal fenestration defects. J Dent Res. (1997) 76:1460-70. doi: $10.1177 / 00220345970760080801$

122. Wikesjö UME, Guglielmoni P, Promsudthi A, Cho K-S, Trombelli L, Selvig KA, et al. Periodontal repair in dogs: effect of rhBMP-2 concentration on regeneration of alveolar bone and periodontal attachment. J Clin Periodontol. (1999) 26:392-400. doi: 10.1034/j.1600-051X.1999.260610.x

123. Selvig KA, Sorensen RG, Wozney JM, Wikesjö UME. Bone repair following recombinant human bone morphogenetic protein-2 stimulated periodontal regeneration. J Periodontol. (2002) 73:1020-9. doi: 10.1902/jop.2002.73.9.1020

124. Choi S-H, Kim C-K, Cho K-S, Huh J-S, Sorensen RG, Wozney JM, et al. Effect of recombinant human bone morphogenetic protein-2/absorbable collagen sponge (rhBMP-2/ACS) on healing in 3-wall intrabony defects in dogs. J Periodontol. (2002) 73:63-72. doi: 10.1902/jop.2002.73.1.63

125. Wikesjö UM, Lim WH, Thomson RC, Cook AD, Wozney JM, Hardwick WR. Periodontal repair in dogs: evaluation of a bioabsorbable space-providing macroporous membrane with recombinant human bone morphogenetic protein-2. J Periodontol. (2003) 74:635-47. doi: 10.1902/jop.2003.74.5.635

126. Wikesjö UM, Xiropaidis AV, Thomson RC, Cook AD, Selvig KA, Hardwick WR. Periodontal repair in dogs: rhBMP-2 significantly enhances bone formation under provisions for guided tissue regeneration. $J$ Clin Periodontol. (2003) 30:705-14. doi: 10.1034/j.1600-051X.2003.00363.x

127. Ripamonti U, Petit J-C. Bone morphogenetic proteins, cementogenesis, myoblastic stem cells and the induction of periodontal tissue regeneration. Cytokine Growth Factor Rev. (2009) 20:489-99. doi: 10.1016/j.cytogfr.2009.10.016

128. Ripamonti U, Crooks J, Petit JC, Rueger DC. Periodontal tissue regeneration by combined applications of recombinant human osteogenic protein-1 and bone morphogenetic protein-2. A pilot study in Chacma baboons (Papio ursinus). Eur J Oral Sci. (2001) 109:241-8. doi: 10.1034/j.1600-0722.2001.00041.x

129. Chiu H-C, Chiang C-Y, Tu H-P, Wikesjö UME, Susin C, Fu E. Effects of bone morphogenetic protein- 6 on periodontal wound healing/regeneration in supraalveolar periodontal defects in dogs. J Clin Periodontol. (2013) 40:624-30. doi: 10.1111/jcpe.12075

130. Bowers G, Feiton F, Middleton C, Glynn D, Sharp S, Mellonig J, et al. Histologic comparison of regeneration in human intrabony defects when osteogenin is combined with demineralized freeze-dried bone allograft and with purified bovine collagen. J Periodontol. (1991) 62:690-702. doi: 10.1902/jop.1991.62.11.690

131. Wikesjö UME, Sorensen RG, Kinoshita A, Jian Li X, Wozney JM. Periodontal repair in dogs: effect of recombinant human bone morphogenetic protein-12 (rhBMP-12) on regeneration of alveolar bone and periodontal attachment. $J$ Clin Periodontol. (2004) 31:662-70. doi: 10.1111/j.1600-051X.2004.00541.x
132. Moore YR, Dickinson DP, Wikesjö UM. Growth/differentiation factor5: a candidate therapeutic agent for periodontal regeneration? A review of pre-clinical data. J Clin Periodontol. (2010) 37:288-98. doi: 10.1111/j.1600-051X.2009.01527.x

133. Smith PC, Martínez C, Cáceres M, Martínez J. Research on growth factors in periodontology. Periodontology. (2015) 67:234-50. doi: 10.1111/prd.12068

134. Chen F-M, Shelton RM, Jin Y, Chapple ILC. Localized delivery of growth factors for periodontal tissue regeneration: role, strategies, and perspectives. Med Res Rev. (2009) 29:472-513. doi: 10.1002/med.20144

135. Stavropoulos A, Wikesjö UME. Growth and differentiation factors for periodontal regeneration: a review on factors with clinical testing. $J$ Periodontal Res. (2012) 47:545-53. doi: 10.1111/j.1600-0765.2012.01478.x

136. Cochran DL, Oh TJ, Mills MP, Clem DS, McClain PK, Schallhorn RA, et al. A randomized clinical trial evaluating rh-FGF- $2 / \beta$-TCP in periodontal defects. J Dent Res. (2016) 95:523-30. doi: 10.1177/0022034516632497

137. Li F, Yu F, Xu X, Li C, Huang D, Zhou X, et al. Evaluation of recombinant human FGF-2 and PDGF-BB in periodontal regeneration: a systematic review and meta-analysis. Sci Rep. (2017) 7:65. doi: 10.1038/s41598-017-00113-y

138. Kitamura M, Akamatsu M, Kawanami M, Furuichi Y, Fujii T, Mori M, et al. Randomized placebo-controlled and controlled non-inferiority phase III trials comparing trafermin, a recombinant human fibroblast growth factor 2 , and enamel matrix derivative in periodontal regeneration in intrabony defects. J Bone Miner Res. (2016) 31:806-14. doi: 10.1002/jbmr.2738

139. Kempen DHR, Creemers LB, Alblas J, Lu L, Verbout AJ, Yaszemski MJ, et al. Growth factor interactions in bone regeneration. Tissue Eng B: Rev. (2010) 16:551-66. doi: 10.1089/ten.teb.2010.0176

140. Bai Y, Yin G, Huang Z, Liao X, Chen X, Yao Y, et al. Localized delivery of growth factors for angiogenesis and bone formation in tissue engineering. Int Immunopharmacol. (2013) 16:214-23. doi: 10.1016/j.intimp.2013.04.001

141. Young CS, Ladd PA, Browning CF, Thompson A, Bonomo J, Shockley K, et al. Release, biological potency, and biochemical integrity of recombinant human platelet-derived growth factor-BB (rhPDGF-BB) combined with AugmentTM Bone Graft or GEM 21S beta-tricalcium phosphate ( $\beta$-TCP). J Controll Release. (2009) 140:250-5. doi: 10.1016/j.jconrel.2009.06.030

142. Ziegler J, Mayr-Wohlfart U, Kessler S, Breitig D, Günther KP. Adsorption and release properties of growth factors from biodegradable implants. J Biomed Mater Res. (2002) 59:422-8. doi: 10.1002/jbm.1258

143. Midy V, Rey C, Bres E, Dard M. Basic fibroblast growth factor adsorption and release properties of calcium phosphate. I Biomed Mater Res. (1998) 41:405-11. doi: 10.1002/(SICI)1097-4636(19980905)41:3<405::AIDJBM10>3.0.CO;2- $\mathrm{H}$

144. Geiger M, Li RH, Friess W. Collagen sponges for bone regeneration with rhBMP-2. Adv Drug Deliv Rev. (2003) 55:1613-29. doi: 10.1016/j.addr.2003.08.010

145. Wikesjö UM, Xiropaidis AV, Thomson RC, Cook AD, Selvig KA, Hardwick WR. Periodontal repair in dogs: space-providing ePTFE devices increase rhBMP-2/ACS-induced bone formation. J Clin Periodontol. (2003) 30:71525. doi: 10.1034/j.1600-051X.2003.00364.x

146. Mitchell AC, Briquez PS, Hubbell JA, Cochran JR. Engineering growth factors for regenerative medicine applications. Acta Biomater. (2016) 30:112. doi: 10.1016/j.actbio.2015.11.007

147. Boerckel JD, Kolambkar YM, Dupont KM, Uhrig BA, Phelps EA, Stevens HY, et al. Effects of protein dose and delivery system on BMP-mediated bone regeneration. Biomaterials. (2011) 32:5241-51. doi: 10.1016/j.biomaterials.2011.03.063

148. Talwar R, Di Silvio L, Hughes FJ, King GN. Effects of carrier release kinetics on bone morphogenetic protein-2-induced periodontal regeneration in vivo. J Clin Periodontol. (2001) 28:340-7. doi: 10.1034/j.1600-051x.2001.028004340.x

149. King GN, King N, Hughes FJ. Effect of two delivery systems for recombinant human bone morphogenetic protein-2 on periodontal regeneration in vivo. $J$ Periodontal Res. (1998) 33:226-36. doi: 10.1111/j.1600-0765.1998.tb02194.x

150. Wei L, Teng F, Deng L, Liu G, Luan M, Jiang J, et al. Periodontal regeneration using bone morphogenetic protein 2 incorporated biomimetic calcium phosphate in conjunction with barrier membrane: a pre-clinical study in dogs. J Clin Periodontol. (2019) 46:1254-63. doi: 10.1111/jcpe. 13195 
151. Matsuse K, Hashimoto Y, Kakinoki S, Yamaoka T, Morita S. Periodontal regeneration induced by porous alpha-tricalcium phosphate with immobilized basic fibroblast growth factor in a canine model of 2-wall periodontal defects. Med Mol Morphol. (2018) 51:48-56. doi: 10.1007/s00795-017-0172-9

152. Omata K, Matsuno T, Asano K, Hashimoto Y, Tabata Y, Satoh T. Enhanced bone regeneration by gelatin- $\beta$-tricalcium phosphate composites enabling controlled release of bFGF. J Tissue Eng Regen Med. (2014) 8:604-11. doi: 10.1002/term.1553

153. Chang P-C, Dovban AS, Lim LP, Chong LY, Kuo MY, Wang C-H. Dual delivery of PDGF and simvastatin to accelerate periodontal regeneration in vivo. Biomaterials. (2013) 34:9990-7. doi: 10.1016/j.biomaterials.2013.09.030

154. Chen F-m, Zhao Y-m, Wu H, Deng Z-h, Wang Q-t, Zhou W, et al. Enhancement of periodontal tissue regeneration by locally controlled delivery of insulin-like growth factor-I from dextranco-gelatin microspheres. J Controll Release. (2006) 114:209-22. doi: 10.1016/j.jconrel.2006.05.014

155. Chen F-M, Zhao Y-M, Zhang R, Jin T, Sun H-H, Wu Z-F, et al. Periodontal regeneration using novel glycidyl methacrylated dextran (Dex-GMA)/gelatin scaffolds containing microspheres loaded with bone morphogenetic proteins. J Controll Release. (2007) 121:81-90. doi: 10.1016/j.jconrel.2007.05.023

156. Giannobile WV, Hernandez RA, Finkelman RD, Ryarr S, Kiritsy CP, D'Andrea $\mathrm{M}$, et al. Comparative effects of plateletderived growth factor$\mathrm{BB}$ and insulin-like growth factor-I, individually and in combination, on periodontal regeneration in Macaca fascicularis. J Periodontal Res. (1996) 31:301-12. doi: 10.1111/j.1600-0765.1996.tb00497.x

157. Zang S, Mu R, Chen F, Wei X, Zhu L, Han B, et al. Injectable chitosan/ $\beta$ glycerophosphate hydrogels with sustained release of BMP-7 and ornidazole in periodontal wound healing of class III furcation defects. Mater Sci Eng C. (2019) 99:919-28. doi: 10.1016/j.msec.2019.02.024

158. Ding T, Li J, Zhang X, Du L, Li Y, Li D, et al. Super-assembled core/shell fibrous frameworks with dual growth factors for in situ cementumligament-bone complex regeneration. Biomater Sci. (2020) 8:2459-71. doi: 10.1039/D0BM00102C

159. Oortgiesen DA, Walboomers XF, Bronckers AL, Meijer GJ, Jansen JA. Periodontal regeneration using an injectable bone cement combined with BMP-2 or FGF-2. J Tissue Eng Regen Med. (2014) 8:202-9. doi: 10.1002/term.1514

160. Wang B, Mastrogiacomo S, Yang F, Shao J, Ong MMA, Chanchareonsook $\mathrm{N}$, et al. Application of BMP-bone cement and FGF-Gel on periodontal tissue regeneration in nonhuman primates. Tissue Eng C Methods. (2019) 25:748-56. doi: 10.1089/ten.tec.2019.0160

161. Sowmya S, Mony U, Jayachandran P, Reshma S, Kumar RA, Arzate H, et al. Tri-layered nanocomposite hydrogel scaffold for the concurrent regeneration of cementum, periodontal ligament, and alveolar bone. Adv Healthc Mater. (2017) 6:1601251. doi: 10.1002/adhm.201601251

162. Guo Z, Bo D, He P, Li H, Wu G, Li Z, et al. Sequential controlled-released dual-drug loaded scaffold for guided bone regeneration in a rat fenestration defect model. J Mater Chem B. (2017) 5:7701-10. doi: 10.1039/C7TB00909G

163. Lee BS, Lee CC, Lin HP, Shih WA, Hsieh WL, Lai CH, et al. A functional chitosan membrane with grafted epigallocatechin-3-gallate and lovastatin enhances periodontal tissue regeneration in dogs. Carbohydr Polym. (2016) 151:790-802. doi: 10.1016/j.carbpol.2016.06.026

164. Xu X, Gu Z, Chen X, Shi C, Liu C, Liu M, et al. An injectable and thermosensitive hydrogel: Promoting periodontal regeneration by controlled-release of aspirin and erythropoietin. Acta Biomater. (2019) 86:235-46. doi: 10.1016/j.actbio.2019.01.001

165. Xiang M, Zhu M, Yang Z, He P, Wei J, Gao X, et al. Dual-functionalized apatite nanocomposites with enhanced cytocompatibility and osteogenesis for periodontal bone regeneration. ACS Biomater Sci Eng. (2020) 6:1704-14. doi: 10.1021/acsbiomaterials.9b01893

166. Jin Q, Anusaksathien O, Webb SA, Printz MA, Giannobile WV. Engineering of tooth-supporting structures by delivery of PDGF gene therapy vectors. Molecular Therapy. (2004) 9:519-26. doi: 10.1016/j.ymthe.2004. 01.016
167. Jin QM, Anusaksathien O, Webb SA, Rutherford RB, Giannobile WV. Gene therapy of bone morphogenetic protein for periodontal tissue engineering. $J$ Periodontol. (2003) 74:202-13. doi: 10.1902/jop.2003.74.2.202

168. Tan Z, Zhao Q, Gong P, Wu Y, Wei N, Yuan Q, et al. Research on promoting periodontal regeneration with human basic fibroblast growth factor-modified bone marrow mesenchymal stromal cell gene therapy. Cytotherapy. (2009) 11:317-25. doi: 10.1080/14653240902824757

169. Chen YL, Chen PK, Jeng LB, Huang CS, Yang LC, Chung HY, et al. Periodontal regeneration using ex vivo autologous stem cells engineered to express the BMP-2 gene: an alternative to alveolaplasty. Gene Ther. (2008) 15:1469-77. doi: 10.1038/gt.2008.131

170. Zhang Y, Miron RJ, Li S, Shi B, Sculean A, Cheng X. Novel MesoPorous BioGlass/silk scaffold containing adPDGF-B and adBMP7 for the repair of periodontal defects in beagle dogs. J Clin Periodontol. (2015) 42:262-71. doi: $10.1111 /$ jcpe. 12364

171. Pilipchuk SP, Fretwurst T, Yu N, Larsson L, Kavanagh NM, Asa'ad F, et al. Micropatterned scaffolds with immobilized growth factor genes regenerate bone and periodontal ligament-like tissues. Adv Healthc Mater. (2018) 7:e1800750. doi: 10.1002/adhm.201800750

172. Gestrelius S, Lyngstadaas SP, Hammarström L. Emdogain-periodontal regeneration based on biomimicry. Clin Oral Investig. (2000) 4:120-5. doi: $10.1007 / \mathrm{s} 007840050127$

173. Hammarstrom L. Enamel matrix, cementum development and regeneration. $J$ Clin Periodontol. (1997) 24:658-68. doi: 10.1111/j.1600-051X.1997.tb00247.x

174. Diekwisch TG. The developmental biology of cementum. Int J Dev Biol. (2001) 45:695-706.

175. Xiong J, Gronthos S, Bartold PM. Role of the epithelial cell rests of Malassez in the development, maintenance and regeneration of periodontal ligament tissues. Periodontology. (2013) 63:217-33. doi: 10.1111/prd.12023

176. Bosshardt DD. Biological mediators and periodontal regeneration: a review of enamel matrix proteins at the cellular and molecular levels. J Clin Periodontol. (2008) 35:87-105. doi: 10.1111/j.1600-051X.2008.01264.x

177. Nishio C, Wazen R, Kuroda S, Moffatt P, Nanci A. Disruption of periodontal integrity induces expression of apin by epithelial cell rests of Malassez. $J$ Periodontal Res. (2010) 45:709-13. doi: 10.1111/j.1600-0765.2010.01288.x

178. Hasegawa N, Kawaguchi $\mathrm{H}$, Ogawa $\mathrm{T}$, Uchida $\mathrm{T}$, Kurihara $\mathrm{H}$. Immunohistochemical characteristics of epithelial cell rests of Malassez during cementum repair. J Periodontal Res. (2003) 38:51-6. doi: 10.1034/j.1600-0765.2003.01636.x

179. Brice GL, Sampson WJ, Sims MR. An ultrastructural evaluation of the relationship between epithelial rests of Malassez and orthodontic root resorption and repair in man. Aust Orthod J. (1991) 12:90-4.

180. Wesselink PR, Beertsen W. The prevalence and distribution of rests of Malassez in the mouse molar and their possible role in repair and maintenance of the periodontal ligament. Arch Oral Biol. (1993) 38:399-403. doi: 10.1016/0003-9969(93)90211-4

181. Sculean A, Berakdar M, Pahl S, Windisch P, Brecx M, Reich E, et al. Patterns of cytokeratin expression in monkey and human periodontium following regenerative and conventional periodontal surgery. J Periodontal Res. (2001) 36:260-8. doi: 10.1034/j.1600-0765.2001.036004260.x

182. Reitan K. Behavior of Malassez' epithelial rests during orthodontic tooth movement. Acta Odontol Scand. (1961) 19:443-68. doi: 10.3109/00016356109043400

183. Miron RJ, Sculean A, Cochran DL, Froum S, Zucchelli G, Nemcovsky C, et al. Twenty years of enamel matrix derivative: the past, the present and the future. J Clin Periodontol. (2016) 43:668-83. doi: 10.1111/jcpe.12546

184. Hammarström L, Heijl L, Gestrelius S. Periodontal regeneration in a buccal dehiscence model in monkeys after application of enamel matrix proteins. $J$ Clin Periodontol. (1997) 24:669-77. doi: 10.1111/j.1600-051X.1997.tb00248.x

185. Sculean A, Donos N, Windisch P, Brecx M, Gera I, Reich E, et al. Healing of human intrabony defects following treatment with enamel matrix proteins or guided tissue regeneration. J Periodontal Res. (1999) 34:310-22. doi: 10.1111/j.1600-0765.1999.tb02259.x

186. Bosshardt DD, Sculean A, Windisch P, Pjetursson BE, Lang NP. Effects of enamel matrix proteins on tissue formation along the roots of human teeth. J Periodontal Res. (2005) 40:158-67. doi: 10.1111/j.1600-0765.2005.00785.x 
187. Sculean A, Chiantella GC, Windisch P, Donos N. Clinical and histologic evaluation of human intrabony defects treated with an enamel matrix protein derivative (Emdogain). Int J Periodontics Restorative Dent. (2000) 20:374-81.

188. Suzuki S, Nagano T, Yamakoshi Y, Gomi K, Arai T, Fukae M, et al. Enamel matrix derivative gel stimulates signal transduction of BMP and TGF- $\beta$. $J$ Dent Res. (2005) 84:510-4. doi: 10.1177/154405910508400605

189. Nagano T, Oida S, Suzuki S, Iwata T, Yamakoshi Y, Ogata Y, et al. Porcine enamel protein fractions contain transforming growth factor- $\beta 1$. $J$ Periodontol. (2006) 77:1688-94. doi: 10.1902/jop.2006.050352

190. Lyngstadaas SP, Lundberg E, Ekdahl H, Andersson C, Gestrelius S. Autocrine growth factors in human periodontal ligament cells cultured on enamel matrix derivative. J Clin Periodontol. (2001) 28:181-8. doi: 10.1034/j.1600-051x.2001.028002181.x

191. Van der Pauw MT, Van den Bos T, Everts V, Beertsen W. Enamel matrixderived protein stimulates attachment of periodontal ligament fibroblasts and enhances alkaline phosphatase activity and transforming growth factor $\beta 1$ release of periodontal ligament and gingival fibroblasts. J Periodontol. (2000) 71:31-43. doi: 10.1902/jop.2000.71.1.31

192. Parkar MH, Tonetti M. Gene Expression profiles of periodontal ligament cells treated with enamel matrix proteins in vitro: analysis using cDNA arrays. J Periodontol. (2004) 75:1539-46. doi: 10.1902/jop.2004.75.11.1539

193. Cochran DL, King GN, Schoolfield J, Velasquez-Plata D, Mellonig JT, Jones A. The effect of enamel matrix proteins on periodontal regeneration as determined by histological analyses. J Periodontol. (2003) 74:1043-55. doi: 10.1902/jop.2003.74.7.1043

194. Donos N, Sculean A, Glavind L, Reich E, Karring T. Wound healing of degree III furcation involvements following guided tissue regeneration and/or Emdogain. A histologic study. J Clin Periodontol. (2003) 30:1061-8. doi: 10.1046/j.0303-6979.2003.00429.x

195. Gkranias ND, Graziani F, Sculean A, Donos N. Wound healing following regenerative procedures in furcation degree III defects: histomorphometric outcomes. Clin Oral Investig. (2012) 16:239-49. doi: 10.1007/s00784-010-0478-7

196. Nibali L, Sultan D, Arena C, Pelekos G, Lin GH, Tonetti M. Periodontal infrabony defects: systematic review of healing by defect morphology following regenerative surgery. J Clin Periodontol. (2021) 48:100-13. doi: $10.1111 /$ jcpe. 13381

197. Shirakata Y, Yoshimoto T, Goto H, Yonamine Y, Kadomatsu H, Miyamoto $\mathrm{M}$, et al. Favorable periodontal healing of 1-wall infrabony defects after application of calcium phosphate cement wall alone or in combination with enamel matrix derivative: a pilot study with canine mandibles. J Periodontol. (2007) 78:889-98. doi: 10.1902/jop.2007.060353

198. Yamamoto S, Masuda H, Shibukawa Y, Yamada S. Combination of bovinederived xenografts and enamel matrix derivative in the treatment of intrabony periodontal defects in dogs. Int J Periodontics Restorative Dent. (2007) 27:471-9.

199. Tu YK, Woolston A, Faggion CM, Jr. Do bone grafts or barrier membranes provide additional treatment effects for infrabony lesions treated with enamel matrix derivatives? A network meta-analysis of randomized-controlled trials. J Clin Periodontol. (2010) 37:59-79. doi: 10.1111/j.1600-051X.2009.01499.x

200. Matarasso M, Iorio-Siciliano V, Blasi A, Ramaglia L, Salvi GE, Sculean A. Enamel matrix derivative and bone grafts for periodontal regeneration of intrabony defects. A systematic review and meta-analysis. Clin Oral Investig. (2015) 19:1581-93. doi: 10.1007/s00784-015-1491-7

201. Troiano G, Laino L, Zhurakivska K, Cicciù M, Lo Muzio L, Lo Russo L. Addition of enamel matrix derivatives to bone substitutes for the treatment of intrabony defects: a systematic review, meta-analysis and trial sequential analysis. J Clin Periodontol. (2017) 44:729-38. doi: 10.1111/jcpe.12742

202. Cortellini P, Pini-Prato G, Nieri M, Tonetti MS. Minimally invasive surgical technique and enamel matrix derivative in intrabony defects: 2. Factors associated with healing outcomes. Int $J$ Periodontics Restorative Dent. (2009) 29:257-65.

203. Cortellini P, Tonetti MS. Clinical and radiographic outcomes of the modified minimally invasive surgical technique with and without regenerative materials: a randomized-controlled trial in intra-bony defects. J Clin Periodontol. (2011) 38:365-73. doi: 10.1111/j.1600-051X.2011.01705.x
204. Cortellini P, Tonetti MS. Clinical concepts for regenerative therapy in intrabony defects. Periodontology. (2015) 68:282-307. doi: $10.1111 /$ prd. 12048

205. Lam LRW, Schilling K, Romas S, Misra R, Zhou Z, Caton JG, et al. Electrospun core-shell nanofibers with encapsulated enamel matrix derivative for guided periodontal tissue regeneration. Dent Mater J. (2021) 2021:advpub. doi: 10.4012/dmj.2020-412

206. Park JS, Pabst AM, Ackermann M, Moergel M, Jung J, Kasaj A. Biofunctionalization of porcine-derived collagen matrix using enamel matrix derivative and platelet-rich fibrin: influence on mature endothelial cell characteristics in vitro. Clin Oral Investig. (2018) 22:909-17. doi: 10.1007/s00784-017-2170-7

207. Stähli A, Miron RJ, Bosshardt DD, Sculean A, Gruber R. Collagen membranes adsorb the transforming growth factor- $\beta$ receptor I kinasedependent activity of enamel matrix derivative. J Periodontol. (2016) 87:58390. doi: 10.1902/jop.2016.150538

208. Miron RJ, Bosshardt DD, Buser D, Zhang Y, Tugulu S, Gemperli A, et al. Comparison of the capacity of enamel matrix derivative gel and enamel matrix derivative in liquid formulation to adsorb to bone grafting materials. J Periodontol. (2015) 86:578-87. doi: 10.1902/jop.2015.140538

209. Shirakata Y, Miron RJ, Nakamura T, Sena K, Shinohara Y, Horai N, et al. Effects of EMD liquid (Osteogain) on periodontal healing in class III furcation defects in monkeys. J Clin Periodontol. (2017) 44:298-307. doi: $10.1111 /$ jcpe. 12663

210. Shirakata Y, Miron RJ, Shinohara Y, Nakamura T, Sena K, Horai N, et al. Healing of two-wall intra-bony defects treated with a novel EMD-liquidA pre-clinical study in monkeys. J Clin Periodontol. (2017) 44:1264-73. doi: $10.1111 /$ jcpe. 12825

211. Grainger S, Willert K. Mechanisms of Wnt signaling and control. Wiley Interdiscip Rev Syst Biol Med. (2018) 2018:e1422. doi: 10.1002/wsbm.1422

212. Yin X, Li J, Salmon B, Huang L, Lim WH, Liu B, et al. Wnt signaling and its contribution to craniofacial tissue homeostasis. J Dent Res. (2015) 94:1487-94. doi: 10.1177/0022034515599772

213. Rooker SM, Liu B, Helms JA. Role of Wnt signaling in the biology of the periodontium. Dev Dyn. (2010) 239:140-7. doi: 10.1002/dvdy.22003

214. Lim WH, Liu B, Cheng D, Williams BO, Mah SJ, Helms JA. Wnt signaling regulates homeostasis of the periodontal ligament. J Periodontal Res. (2014) 49:751-9. doi: 10.1111/jre.12158

215. Lim WH, Liu B, Mah S-j, Yin X, Helms JA. Alveolar bone turnover and periodontal ligament width are controlled by Wnt. J Periodontol. (2015) 86:319-26. doi: 10.1902/jop.2014.140286

216. Kuchler U, Schwarze UY, Dobsak T, Heimel P, Bosshardt DD, Kneissel M, et al. Dental and periodontal phenotype in sclerostin knockout mice. Int J Oral Sci. (2014) 6:70-6. doi: 10.1038/ijos.2014.12

217. Lu J, Duan Y, Zhang M, Wu M, Wang Y. Expression of Wnt3a, Wnt10b, $\beta$-catenin and DKK1 in periodontium during orthodontic tooth movement in rats. Acta Odontol Scand. (2016) 74:217-23. doi: 10.3109/00016357.2015.1090011

218. Turkkahraman H, Yuan X, Salmon B, Chen C-H, Brunski JB, Helms JA. Root resorption and ensuing cementum repair by $\mathrm{Wnt} / \beta$-catenin dependent mechanism. Am J Orthodont Dentofac Orthoped. (2020) 158:1627. doi: 10.1016/j.ajodo.2019.06.021

219. Han P, Ivanovski S, Crawford R, Xiao Y. Activation of the canonical Wnt signaling pathway induces cementum regeneration. J Bone Miner Res. (2015) 30:1160-74. doi: 10.1002/jbmr.2445

220. Yao Y, Kauffmann F, Maekawa S, Sarment LV, Sugai JV, Schmiedeler CA, et al. Sclerostin antibody stimulates periodontal regeneration in large alveolar bone defects. Sci Rep. (2020) 10:16217. doi: 10.1038/s41598-020-73026-y

221. Zhang Q, Chen L, Chen B, Chen C, Chang J, Xiao Y, et al. Lithium-calciumsilicate bioceramics stimulating cementogenic/osteogenic differentiation of periodontal ligament cells and periodontal regeneration. Appl Mater Today. (2019) 16:375-87. doi: 10.1016/j.apmt.2019.06.011

222. Park CH, Oh J-H, Jung H-M, Choi Y, Rahman SU, Kim S, et al. Effects of the incorporation of $\varepsilon$-aminocaproic acid/chitosan particles to fibrin on cementoblast differentiation and cementum regeneration. Acta Biomater. (2017) 61:134-43. doi: 10.1016/j.actbio.2017. 07.039 
223. Rahman SU, Park CH, Baek J-H, Ryoo H-M, Woo KM. Fibrin-Enhanced Canonical Wnt Signaling Directs Plasminogen Expression in Cementoblasts. Int J Mol Sci. (2017) 18:2380. doi: 10.3390/ijms18112380

224. Ren Y, Han X, Ho SP, Harris SE, Cao Z, Economides AN, et al. Removal of SOST or blocking its product sclerostin rescues defects in the periodontitis mouse model. FASEB J. (2015) 29:2702-11. doi: 10.1096/fj.14-265496

225. Taut AD, Jin Q, Chung J-H, Galindo-Moreno P, Yi ES, Sugai JV, et al. Sclerostin antibody stimulates bone regeneration after experimental periodontitis. J Bone Miner Res. (2013) 28:2347-56. doi: 10.1002/jbmr.1984

226. Adamowicz K, Wang H, Jotwani R, Zeller I, Potempa J, Scott DA. Inhibition of GSK3 abolishes bacterial-induced periodontal bone loss in mice. Mol Med. (2012) 18:1190-6. doi: 10.2119/molmed.2012.00180

227. Masuki H, Okudera T, Watanebe T, Suzuki M, Nishiyama K, Okudera H, et al. Growth factor and pro-inflammatory cytokine contents in platelet-rich plasma (PRP), plasma rich in growth factors (PRGF), advanced platelet-rich fibrin (A-PRF), and concentrated growth factors (CGF). Int J Implant Dent. (2016) 2:19. doi: 10.1186/s40729-016-0052-4

228. Badran Z, Abdallah M-N, Torres J, Tamimi F. Platelet concentrates for bone regeneration: current evidence and future challenges. Platelets. (2018) 29:105-12. doi: 10.1080/09537104.2017.1327656

229. Kobayashi E, Flückiger L, Fujioka-Kobayashi M, Sawada K, Sculean A, Schaller B, et al. Comparative release of growth factors from PRP, PRF, and advanced-PRF. Clin Oral Investig. (2016) 20:2353-60. doi: 10.1007/s00784-016-1719-1

230. Appel TR, Pötzsch B, Müller J, Von Lindern J-J, Bergé SJ, Reich RH. Comparison of three different preparations of platelet concentrates for growth factor enrichment. Clin Oral Implants Res. (2002) 13:522-8. doi: 10.1034/j.1600-0501.2002.130512.x

231. Miron RJ, Moraschini V, Fujioka-Kobayashi M, Zhang Y, Kawase T, Cosgarea $\mathrm{R}$, et al. Use of platelet-rich fibrin for the treatment of periodontal intrabony defects: a systematic review and meta-analysis. Clin Oral Investig. (2021) 25:2461-78. doi: 10.1007/s00784-021-03825-8

232. Nagata MJ, de Campos N, Messora MR, Pola NM, Santinoni CS, Bomfim $\mathrm{SR}$, et al. Platelet-rich plasma, low-level laser therapy, or their combination promotes periodontal regeneration in fenestration defects: a preliminary in vivo study. J Periodontol. (2014) 85:770-8. doi: 10.1902/jop.2013.130318

233. Keles GC, Cetinkaya BO, Baris S, Albayrak D, Simsek SB. Comparison of platelet pellet with or without guided tissue regeneration in the treatment of class II furcation defects in dogs. Clin Oral Investig. (2009) 13:393-400. doi: 10.1007/s00784-008-0245-1

234. Duan X, Lin Z, Lin X, Wang Z, Wu Y, Ji M, et al. Study of platelet-rich fibrin combined with rat periodontal ligament stem cells in periodontal tissue regeneration. J Cell Mol Med. (2018) 22:1047-55.

235. Kornsuthisopon C, Pirarat N, Osathanon T, Kalpravidh C. Autologous platelet-rich fibrin stimulates canine periodontal regeneration. Sci Rep. (2020) 10:1850. doi: 10.1038/s41598-020-58732-x

236. Krampera M, Le Blanc K. Mesenchymal stromal cells: putative microenvironmental modulators become cell therapy. Cell Stem Cell. (2021) 28:1708-25. doi: 10.1016/j.stem.2021.09.006

237. Li Q, Yang G, Li J, Ding M, Zhou N, Dong H, et al. Stem cell therapies for periodontal tissue regeneration: a network meta-analysis of preclinical studies. Stem Cell Res Ther. (2020) 11:427. doi: 10.1186/s13287-020-01938-7

238. Tassi SA, Sergio NZ, Misawa MYO, Villar CC. Efficacy of stem cells on periodontal regeneration: systematic review of pre-clinical studies. $J$ Periodontal Res. (2017) 52:793-812. doi: 10.1111/jre.12455

239. Vaquette C, Saifzadeh S, Farag A, Hutmacher DW, Ivanovski S. Periodontal tissue engineering with a multiphasic construct and cell sheets. J Dent Res. (2019) 98:673-81. doi: 10.1177/0022034519837967

240. Dan H, Vaquette C, Fisher AG, Hamlet SM, Xiao Y, Hutmacher DW, et al. The influence of cellular source on periodontal regeneration using calcium phosphate coated polycaprolactone scaffold supported cell sheets. Biomaterials. (2014) 35:113-22. doi: 10.1016/j.biomaterials.2013.09.074

241. Tsumanuma Y, Iwata T, Washio K, Yoshida T, Yamada A, Takagi R, et al. Comparison of different tissue-derived stem cell sheets for periodontal regeneration in a canine 1-wall defect model. Biomaterials. (2011) 32:581925. doi: 10.1016/j.biomaterials.2011.04.071

242. Marchesan JT, Scanlon CS, Soehren S, Matsuo M, Kapila YL. Implications of cultured periodontal ligament cells for the clinical and experimental setting: a review. Arch Oral Biol. (2011) 56:933-43. doi: 10.1016/j.archoralbio.2011.03.003

243. Bartold PM, Gronthos S. Standardization of criteria defining periodontal ligament stem cells. J Dent Res. (2017) 96:487-90. doi: 10.1177/0022034517697653

244. Luan X, Dangaria S, Ito Y, Walker CG, Jin T, Schmidt MK, et al. Neural crest lineage segregation: a blueprint for periodontal regeneration. J Dent Res. (2009) 88:781-91. doi: 10.1177/0022034509340641

245. Dominici M, Le Blanc K, Mueller I, Slaper-Cortenbach I, Marini F, Krause $D$, et al. Minimal criteria for defining multipotent mesenchymal stromal cells. The International Society for Cellular Therapy position statement. Cytotherapy. (2006) 8:315-7. doi: 10.1080/14653240600855905

246. Zhu W, Liang M. Periodontal ligament stem cells: current status, concerns, and future prospects. Stem Cells Int. (2015) 2015:972313. doi: $10.1155 / 2015 / 972313$

247. De Luca M, Aiuti A, Cossu G, Parmar M, Pellegrini G, Robey PG. Advances in stem cell research and therapeutic development. Nat Cell Biol. (2019) 21:801-11. doi: 10.1038/s41556-019-0344-Z

248. Menicanin D, Mrozik KM, Wada N, Marino V, Shi S, Bartold PM, et al. Periodontal-ligament-derived stem cells exhibit the capacity for long-term survival, self-renewal, and regeneration of multiple tissue types in vivo. Stem Cells Dev. (2014) 23:1001-11. doi: 10.1089/scd.2013.0490

249. Lei M, Li K, Li B, Gao L-N, Chen F-M, Jin Y. Mesenchymal stem cell characteristics of dental pulp and periodontal ligament stem cells after in vivo transplantation. Biomaterials. (2014) 35:6332-43. doi: 10.1016/j.biomaterials.2014.04.071

250. San Miguel SM, Fatahi MR, Li H, Igwe JC, Aguila HL, Kalajzic I. Defining a visual marker of osteoprogenitor cells within the periodontium. J Periodontal Res. (2010) 45:60-70. doi: 10.1111/j.1600-0765.2009.01201.x

251. Lallier TE, Spencer A. Use of microarrays to find novel regulators of periodontal ligament fibroblast differentiation. Cell Tissue Res. (2007) 327:93-109. doi: 10.1007/s00441-006-0282-5

252. Nakahara T, Nakamura T, Kobayashi E, Kuremoto K, Matsuno T, Tabata $\mathrm{Y}$, et al. In situ tissue engineering of periodontal tissues by seeding with periodontal ligament-derived cells. Tissue Eng. (2004) 10:537-44. doi: $10.1089 / 107632704323061898$

253. Liu Y, Zheng Y, Ding G, Fang D, Zhang C, Bartold PM, et al. Periodontal ligament stem cell-mediated treatment for periodontitis in miniature swine. Stem Cells. (2008) 26:1065-73. doi: 10.1634/stemcells.2007-0734

254. Chen FM, Gao LN, Tian BM, Zhang XY, Zhang YJ, Dong GY, et al. Treatment of periodontal intrabony defects using autologous periodontal ligament stem cells: a randomized clinical trial. Stem Cell Res Ther. (2016) 7:33. doi: 10.1186/s13287-016-0288-1

255. Sánchez N, Fierravanti L, Núñez J, Vignoletti F, González-Zamora M, Santamaría S, et al. Periodontal regeneration using a xenogeneic bone substitute seeded with autologous periodontal ligament-derived mesenchymal stem cells: a 12-month quasi-randomized controlled pilot clinical trial. J Clin Periodontol. (2020) 47:1391-402. doi: 10.1111/jcpe.13368

256. Bright R, Hynes K, Gronthos S, Bartold PM. Periodontal ligament-derived cells for periodontal regeneration in animal models: a systematic review. $J$ Periodontal Res. (2015) 50:160-72. doi: 10.1111/jre.12205

257. Magalhães FD, Sarra G, Carvalho GL, Pedroni ACF, Marques MM, Chambrone L, et al. Dental tissue-derived stem cell sheet biotechnology for periodontal tissue regeneration: a systematic review. Arch Oral Biol. (2021) 129:105182. doi: 10.1016/j.archoralbio.2021.105182

258. Iwata T, Yamato M, Washio K, Yoshida T, Tsumanuma Y, Yamada A, et al. Periodontal regeneration with autologous periodontal ligament-derived cell sheets-a safety and efficacy study in ten patients. Regen Ther. (2018) 9:38-44. doi: 10.1016/j.reth.2018.07.002

259. Yang Y, Rossi FMV, Putnins EE. Periodontal regeneration using engineered bone marrow mesenchymal stromal cells. Biomaterials. (2010) 31:8574-82. doi: 10.1016/j.biomaterials.2010.06.026

260. Wei N, Gong P, Liao D, Yang X, Li X, Liu Y, et al. Auto-transplanted mesenchymal stromal cell fate in periodontal tissue of beagle dogs. Cytotherapy. (2010) 12:514-21. doi: 10.3109/146532410037 09702

261. Hasegawa N, Kawaguchi H, Hirachi A, Takeda K, Mizuno N, Nishimura $\mathrm{M}$, et al. Behavior of transplanted bone marrow-derived mesenchymal 
stem cells in periodontal defects. J Periodontol. (2006) 77:1003-7. doi: 10.1902/jop.2006.050341

262. Yu N, Oortgiesen DAW, Bronckers ALJJ, Yang F, Walboomers XF, Jansen JA. Enhanced periodontal tissue regeneration by periodontal cell implantation. $J$ Clin Periodontol. (2013) 40:698-706. doi: 10.1111/jcpe.12113

263. Yu N, Bronckers AL, Oortgiesen DA, Yan X, Jansen JA, Yang F, et al. Periodontal cell implantation contributes to the regeneration of the periodontium in an indirect way. Tissue Eng Part A. (2015) 21:166-73. doi: 10.1089/ten.tea.2014.0151

264. Iwasaki K, Akazawa K, Nagata M, Komaki M, Honda I, Morioka C, et al. The fate of transplanted periodontal ligament stem cells in surgically created periodontal defects in rats. Int J Mol Sci. (2019) 20:192. doi: 10.3390/ijms 20010192

265. Han J, Menicanin D, Marino V, Ge S, Mrozik K, Gronthos S, et al. Assessment of the regenerative potential of allogeneic periodontal ligament stem cells in a rodent periodontal defect model. J Periodontal Res. (2014) 49:333-45. doi: $10.1111 /$ jre.12111

266. Berglund AK, Fortier LA, Antczak DF, Schnabel LV. Immunoprivileged no more: measuring the immunogenicity of allogeneic adult mesenchymal stem cells. Stem Cell Res Ther. (2017) 8:288. doi: 10.1186/s13287-017-0742-8

267. Preda MB, Neculachi CA, Fenyo IM, Vacaru A-M, Publik MA, Simionescu $\mathrm{M}$, et al. Short lifespan of syngeneic transplanted MSC is a consequence of in vivo apoptosis and immune cell recruitment in mice. Cell Death Dis. (2021) 12:566. doi: 10.1038/s41419-021-03839-w

268. Stabler CL, Li Y, Stewart JM, Keselowsky BG. Engineering immunomodulatory biomaterials for type 1 diabetes. Nat Rev Mater. (2019) 4:429-50. doi: 10.1038/s41578-019-0112-5

269. Zhang J, Huang X, Wang H, Liu X, Zhang T, Wang Y, et al. The challenges and promises of allogeneic mesenchymal stem cells for use as a cell-based therapy. Stem Cell Res Ther. (2015) 6:234. doi: 10.1186/s13287-015-0240-9

270. Swartzlander MD, Blakney AK, Amer LD, Hankenson KD, Kyriakides TR, Bryant SJ. Immunomodulation by mesenchymal stem cells combats the foreign body response to cell-laden synthetic hydrogels. Biomaterials. (2015) 41:79-88. doi: 10.1016/j.biomaterials.2014.11.020

271. Ding J, Chen B, Lv T, Liu X, Fu X, Wang Q, et al. Bone marrow mesenchymal stem cell-based engineered cartilage ameliorates polyglycolic acid/polylactic acid scaffold-induced inflammation through M2 polarization of macrophages in a pig model. Stem Cells Transl Med. (2016) 5:1079-89. doi: $10.5966 /$ sctm.2015-0263

272. Wada N, Tomokiyo A, Gronthos S, Bartold PM. Immunomodulatory properties of PDLSC and relevance to periodontal regeneration. Curr Oral Health Rep. (2015) 2:245-51. doi: 10.1007/s40496-015-0062-y

273. Nagata M, Iwasaki K, Akazawa K, Komaki M, Yokoyama N, Izumi $\mathrm{Y}$, et al. Conditioned medium from periodontal ligament stem cells enhances periodontal regeneration. Tissue Eng Part A. (2016) 23:367-77. doi: 10.1089/ten.tea.2016.0274

274. Zhang Z, Shuai Y, Zhou F, Yin J, Hu J, Guo S, et al. PDLSCs regulate angiogenesis of periodontal ligaments via VEGF transferred by exosomes in periodontitis. Int J Med Sci. (2020) 17:558-67. doi: 10.7150/ijms.40918

275. Qiu J, Wang X, Zhou H, Zhang C, Wang Y, Huang J, et al. Enhancement of periodontal tissue regeneration by conditioned media from gingiva-derived or periodontal ligament-derived mesenchymal stem cells: a comparative study in rats. Stem Cell Res Ther. (2020) 11:42. doi: 10.1186/s13287-019-1546-9

276. Novello S, Pellen-Mussi P, Jeanne S. Mesenchymal stem cell-derived small extracellular vesicles as cell-free therapy: perspectives in periodontal regeneration. J Periodontal Res. (2021) 56:433-42. doi: 10.1111/jre.12866

277. Chew JRJ, Chuah SJ, Teo KYW, Zhang S, Lai RC, Fu JH, et al. Mesenchymal stem cell exosomes enhance periodontal ligament cell functions and promote periodontal regeneration. Acta Biomater. (2019) 89:252-64. doi: 10.1016/j.actbio.2019.03.021

278. Liu L, Guo S, Shi W, Liu Q, Huo F, Wu Y, et al. Bone marrow mesenchymal stem cell-derived small extracellular vesicles promote periodontal regeneration. Tissue Engineering Part A. (2020) 27:962-76. doi: 10.1089/ten.tea.2020.0141

279. Mohammed E, Khalil E, Sabry D. Effect of adipose-derived stem cells and their exo as adjunctive therapy to nonsurgical periodontal treatment: a histologic and histomorphometric study in rats. Biomolecules. (2018) 8:167. doi: 10.3390/biom8040167

280. Wei J, Song Y, Du Z, Yu F, Zhang Y, Jiang N, et al. Exosomes derived from human exfoliated deciduous teeth ameliorate adult bone loss in mice through promoting osteogenesis. J Mol Histol. (2020) 51:455-66. doi: 10.1007/s10735-020-09896-3

281. Shen Z, Kuang S, Zhang Y, Yang M, Qin W, Shi X, et al. Chitosan hydrogel incorporated with dental pulp stem cell-derived exosomes alleviates periodontitis in mice via a macrophage-dependent mechanism. Bioactive Mater. (2020) 5:1113-26. doi: 10.1016/j.bioactmat.2020.07.002

282. Sordi V, Malosio ML, Marchesi F, Mercalli A, Melzi R, Giordano T, et al. Bone marrow mesenchymal stem cells express a restricted set of functionally active chemokine receptors capable of promoting migration to pancreatic islets. Blood. (2005) 106:419-27. doi: 10.1182/blood-2004-09-3507

283. Du L, Yang P, Ge S. Stromal cell-derived factor-1 significantly induces proliferation, migration, and collagen type I expression in a human periodontal ligament stem cell subpopulation. J Periodontol. (2012) 83:37988. doi: 10.1902/jop.2011.110201

284. Trubiani O, Isgro A, Zini N, Antonucci I, Aiuti F, Di Primio R, et al. Functional interleukin-7/interleukin-7R $\alpha$, and SDF-1 $\alpha / C X C R 4$ are expressed by human periodontal ligament derived mesenchymal stem cells. J Cell Physiol. (2008) 214:706-13. doi: 10.1002/jcp.21266

285. Li S, Tu Q, Zhang J, Stein G, Lian J, Yang PS, et al. Systemically transplanted bone marrow stromal cells contributing to bone tissue regeneration. J Cell Physiol. (2008) 215:204-9. doi: 10.1002/jcp.21302

286. Zhou J, Shi S, Shi Y, Xie H, Chen L, He Y, et al. Role of bone marrow-derived progenitor cells in the maintenance and regeneration of dental mesenchymal tissues. J Cell Physiol. (2011) 226:2081-90. doi: 10.1002/jcp.22538

287. Kaku M, Kitami M, Rosales Rocabado JM Ida T, Akiba Y, Uoshima K. Recruitment of bone marrow-derived cells to the periodontal ligament via the stromal cell-derived factor- $1 / \mathrm{C}-\mathrm{X}-\mathrm{C}$ chemokine receptor type 4 axis. $J$ Periodontal Res. (2017) 52:686-94. doi: 10.1111/jre.12433

288. Liu H, Li M, Du L, Yang P, Ge S. Local administration of stromal cellderived factor- 1 promotes stem cell recruitment and bone regeneration in a rat periodontal bone defect model. Mater Sci Eng C. (2015) 53:83-94. doi: 10.1016/j.msec.2015.04.002

289. Cai X, Yang F, Walboomers XF, Wang Y, Jansen JA, van den Beucken J, et al. Periodontal regeneration via chemoattractive constructs. J Clin Periodontol. (2018) 45:851-60. doi: 10.1111/jcpe.12928

290. Wang F, Du L, Ge S. PTH/SDF- $1 \alpha$ cotherapy induces CD90+CD34- stromal cells migration and promotes tissue regeneration in a rat periodontal defect model. Sci Rep. (2016) 6:30403. doi: 10.1038/srep30403

291. Tan J, Zhang M, Hai Z, Wu C, Lin J, Kuang W, et al. Sustained release of two bioactive factors from supramolecular hydrogel promotes periodontal bone regeneration. ACS Nano. (2019) 13:5616-22. doi: 10.1021/acsnano.9b00788

292. He XT, Li X, Xia Y, Yin Y, Wu RX, Sun HH, et al. Building capacity for macrophage modulation and stem cell recruitment in highstiffness hydrogels for complex periodontal regeneration: experimental studies in vitro and in rats. Acta Biomater. (2019) 88:162-80. doi: 10.1016/j.actbio.2019.02.004

293. Langer R, Vacanti JP. Tissue engineering. Science. (1993) 260:920-6. doi: $10.1126 /$ science. 8493529

294. Vacanti CA. The history of tissue engineering. J Cell Mol Med. (2006) 10:569-76. doi: 10.1111/j.1582-4934.2006.tb00421.x

295. Berthiaume F, Maguire TJ, Yarmush ML. Tissue engineering and regenerative medicine: history, progress, and challenges. Annu Rev Chem Biomol Eng. (2011) 2:403-30. doi: 10.1146/annurev-chembioeng-061010-114257

296. Paternoster JL, Vranckx JJ. State of the art of clinical applications of tissue engineering in 2021. Tissue Eng B: Rev. (2021). doi: $10.1089 /$ ten.teb.2021.0017

297. Bartold PM, McCulloch CA, Narayanan AS, Pitaru S. Tissue engineering: a new paradigm for periodontal regeneration based on molecular and cell biology. Periodontology. (2000) 24:253-69. doi: 10.1034/j.1600-0757.2000.2240113.x

298. Murphy WL, Mooney DJ. Controlled delivery of inductive proteins, plasmid DNA and cells from tissue engineering matrices. J Periodontal Res. (1999) 34:413-9. doi: 10.1111/j.1600-0765.1999.tb02275.x 
299. Bell E. Strategy for the selection of scaffolds for tissue engineering. Tissue Eng. (1995) 1:163-79. doi: 10.1089/ten.1995.1.163

300. Ivanovski S, Vaquette C, Gronthos S, Hutmacher DW, Bartold PM. Multiphasic Scaffolds for Periodontal Tissue Engineering. J Dent Res. (2014) 93:1212-21. doi: 10.1177/0022034514544301

301. Bartold PM, Gronthos S, Ivanovski S, Fisher A, Hutmacher DW. Tissue engineered periodontal products. J Periodontal Res. (2016) 51:1-15. doi: $10.1111 /$ jre. 12275

302. Kroeze RJ, Helder MN, Govaert LE, Smit TH. Biodegradable polymers in bone tissue engineering. Materials. (2009) 2:833-56. doi: 10.3390/ma2030833

303. Abbah SA, Lam CXL, Hutmacher DW, Goh JCH, Wong H-K. Biological performance of a polycaprolactone-based scaffold used as fusion cage device in a large animal model of spinal reconstructive surgery. Biomaterials. (2009) 30:5086-93. doi: 10.1016/j.biomaterials.2009.05.067

304. Rasperini G, Pilipchuk SP, Flanagan CL, Park CH, Pagni G, Hollister SJ, et al. 3D-printed bioresorbable scaffold for periodontal repair. J Dent Res. (2015) 94(9 Suppl):153s-7s. doi: 10.1177/0022034515588303

305. Staples RJ, Ivanovski S, Vaquette C. Fibre guiding scaffolds for periodontal tissue engineering. J Periodontal Res. (2020) 55:331-41. doi: $10.1111 /$ jre. 12729

306. Park $\mathrm{CH}$. Biomaterial-based approaches for regeneration of periodontal ligament and cementum using 3D platforms. Int J Mol Sci. (2019) 20:4364. doi: 10.3390/ijms20184364

307. Jiang W, Li L, Zhang D, Huang S, Jing Z, Wu Y, et al. Incorporation of aligned PCL-PEG nanofibers into porous chitosan scaffolds improved the orientation of collagen fibers in regenerated periodontium. Acta Biomater. (2015) 25:240-52. doi: 10.1016/j.actbio.2015.07.023
308. Park CH, Rios HF, Jin Q, Sugai JV, Padial-Molina M, Taut AD, et al. Tissue engineering bone-ligament complexes using fiber-guiding scaffolds. Biomaterials. (2012) 33:137-45. doi: 10.1016/j.biomaterials.2011. 09.057

309. Imber J-C, Bosshardt DD, Stähli A, Saulacic N, Deschner J, Sculean A. Pre-clinical evaluation of the effect of a volume-stable collagen matrix on periodontal regeneration in two-wall intrabony defects. J Clin Periodontol. (2021) 48:560-9. doi: 10.1111/jcpe.13426

Conflict of Interest: The authors declare that the research was conducted in the absence of any commercial or financial relationships that could be construed as a potential conflict of interest.

Publisher's Note: All claims expressed in this article are solely those of the authors and do not necessarily represent those of their affiliated organizations, or those of the publisher, the editors and the reviewers. Any product that may be evaluated in this article, or claim that may be made by its manufacturer, is not guaranteed or endorsed by the publisher.

Copyright (c) 2022 Fraser, Caton and Benoit. This is an open-access article distributed under the terms of the Creative Commons Attribution License (CC BY). The use, distribution or reproduction in other forums is permitted, provided the original author(s) and the copyright owner(s) are credited and that the original publication in this journal is cited, in accordance with accepted academic practice. No use, distribution or reproduction is permitted which does not comply with these terms. 